Research Report No. 12/2013

\title{
La Violación Del Derecho Indígena: Empresas Mineras Canadienses En Guatemala (Breaching Indigenous Law: Canadian Mining in Guatemala)
}

Shin Imai

Osgoode Hall Law School of York University, simai@osgoode.yorku.ca

Ladan Mehranvar

Jennifer Sander

Follow this and additional works at: http:/ / digitalcommons.osgoode.yorku.ca/clpe

\section{Recommended Citation}

Imai, Shin; Mehranvar, Ladan; and Sander, Jennifer, "La Violación Del Derecho Indígena: Empresas Mineras Canadienses En Guatemala (Breaching Indigenous Law: Canadian Mining in Guatemala)" (2013). Comparative Research in Law \& Political Economy. Research Paper No. 12/2013.

http://digitalcommons.osgoode.yorku.ca/clpe/261 


\section{OSGOODE}

OSGOODE HALL LAW SCHOOL YORK UNIVERSITY

\section{OSGOODE HALL LAW SCHOOL}

Comparative Research in Law \& Political Economy

RESEARCH PAPER SERIES

Research Paper No. 12/2013

\section{LA VIOLACIÓN DEL DERECHO INDÍGENA:}

EMPRESAS MINERAS CANADIENSES EN GUATEMALA (Breaching Indigenous Law: Canadian Mining in Guatemala)

Shin Imai

Editors:

Peer Zumbansen (Osgoode Hall Law School, Toronto, Director Comparative Research in Law and Political Economy)

John W. Cioffi (University of California at Riverside)

Leeanne Footman (Osgoode Hall Law School, Toronto, Production Editor)

Comparative Research in Law \& Political Economy 


\title{
LA VIOLACIÓN DEL DERECHO INDÍGENA: EMPRESAS MINERAS CANADIENSES EN GUATEMALA
}

\author{
(Breaching Indigenous Law: Canadian Mining in Guatemala)
}

\section{Resumen}

El presente es un estudio acerca de una pequeña comunidad indígena en Guatemala, que desafió a una poderosa compañía minera canadiense mediante un voto comunitario sobre la autorización o no de la actividad de minería en su territorio. El resultado de la votación -impedir dicha actividadno ha sido acatado por la empresa canadiense. El diferendo se desarrolla sobre un trasfondo de intimidación y violencia. Este estudio analiza la actuación de los principales involucrados en el conflicto -la compañía minera, el gobierno guatemalteco, el Banco Mundial y el gobierno de Canadá-, y concluye que todos ellos tienen un interés en la rentabilidad de la mina. Se observa una clara deficiencia en los controles contables como para asegurar que el pueblo indígena esté siendo tratado con justicia. Haciendo suyas las ideas que recoge el Informe sobre las Conferencias Nacionales en torno a la Responsabilidad Social Corporativa [RSC] y la Industria Extractiva Canadiense en los Países en Desarrollo, publicado en marzo de 2007, nuestro estudio sugiere que los tribunales canadienses parecen ser un foro capaz de juzgar las acciones de las partes en disputa.

\footnotetext{
Abstract

This is a case study of a small Indigenous community in Guatemala that defied a powerful Canadian mining company by holding a community vote on whether to allow mining on its territory. The result of the vote-to stop mining activity on its territory - has not been honoured by the Canadian mining company. The dispute is being played out against a backdrop of intimidation and violence. The study reviews the major players in the dispute - the mining company, the Guatemalan government, the World Bank and the Canadian government - and concludes that they all have a stake in the profitability of the mine. There is a clear deficiency in the checks and balances needed to ensure that the Indigenous people are dealt with fairly. Drawing on ideas from the National Roundtables on Corporate Social Responsibility ("CSR") and the Canadian Extractive Industry in Developing Countries (released in March 2007), the study suggests that at the present time, Canadian courts may be the only forum capable of holding the major actors accountable for their actions.
} 


\title{
LA VIOLACIÓN DEL DERECHO INDÍGENA: EMPRESAS MINERAS CANADIENSES EN GUATEMALA* (Breaching Indigenous Law: Canadian Mining in Guatemala)
}

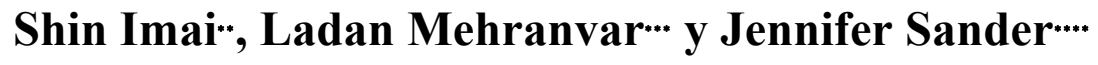

\begin{abstract}
- Artículo publicado bajo el título "Breaching Indigenous Law: Canadian Mining in Guatemala", en la revista Indigenous Law Journal, vol. 6, nro. 1, 2007. Los hechos que se refieren en este trabajo han sido actualizados por Bernadette Maheandiran en "Goldcorp and HudBay in Guatemala (August 2011 Update)" (2011), en internet: http://papers.ssrn.com/sol3/papers.cfm?abstract id=1973070; y por Bernadette Maheandiran, Jessica DiFederico, Rolando Aguilera y Shin Imai en "Goldcorp and HudBay Minerals in Guatemala (2010 Update)" (2010) Osgoode CLPE Research Paper No. 09/2010, en internet: http://papers.ssrn.com/sol3/papers.cfm?abstract_id=1595157. Véase también un artículo relacionado, sobre la mina El Estor, de la que fue propietaria HudBay Minerals, en internet http://ssrn.com/abstract $=2143679$

" Shin Imai es profesor adjunto en la Facultad de Derecho Osgoode Hall, Universidad de York, Toronto, Canadá. El autor quiere agradecer a Jennifer O’Dell y Valerie Crystal por su ayuda editorial, y al Lic. Francisco A. Gómez por la traducción. Esta es una iniciativa del Proyecto Justicia y Responsabilidad Corporativa.

... Ladan Mehranvar (B.Sc., M.Sc., LL.B.) es graduada de la Facultad de Derecho Osgoode Hall.

.... Jennifer Sander es graduada de la Facultad de Derecho Osgoode Hall. Es también graduada como B.A.Sc en la Universidad de Ottawa, Canadá.
\end{abstract}


I INTRODUCCIÓN

II LOS INTERESES EXTRANJEROS Y LA HISTORIA DE GUATEMALA

III EL PROYECTO MARLIN

IV LA DECISIÓN DEL PUEBLO INDÍGENA DE SIPACAPA

V ¿EJERCICIO DEL DERECHO INDÍGENA, O EJERCICIO DE LA LEY GUATEMALTECA POR EL PUEBLO INDÍGENA?

VI DESEQUILIBRIO DEL PODER

VII LIMITACIONES DENTRO DE GUATEMALA

VIII LIMITACIONES INTERNACIONALES SOBRE LOS ACTORES NO INDÍGENAS

IX ¿CUÁL ES LA REPONSABILIDAD DEL GOBIERNO CANADIENSE?

X CONCLUSIONES

\section{INTRODUCCIÓN}

En las páginas que siguen describiremos el diferendo existente entre la compañía minera canadiense Glamis Gold (ahora Goldcorp) ${ }^{1}$ y la población indígena del distrito de San Marcos en Guatemala. Este es un estudio que se concibió tras las visitas de Shin Imai a ese país en 2004, y un verano que pasó Ladan Mehranvar en 2005 en la zona de San Marcos. Es justo decir que

\footnotetext{
${ }^{1}$ En noviembre de 2006, Goldcorp Inc. se fusionó con Glamis mediante un acuerdo por 21,3 mil millones de dólares norteamericanos. El director general de Glamis, Kevin McArthur, fue nombrado director general de Goldcorp. En el resto de este artículo emplearemos el nombre Glamis cuando haya que hacer referencia a acontecimientos históricos correspondientes propiamente a dicha empresa, y cuando tratemos temas más actuales utilizaremos el nombre Goldcorp. Véase "Goldcorp and Glamis Agree to US \$21.3 Billion Combination Creating the World's Premier Gold Mining Company; en internet: http://money.cnn.com/news/newsfeeds/articles/marketwire/06159012.htm
} 
ambos estamos impresionados por lo que vimos y por lo que hemos conocido desde entonces ${ }^{2}$.

Glamis Gold comenzó en 1999 el trabajo preliminar en la mina a cielo abierto, y muy pronto la población indígena manifestó su preocupación acerca de los posibles impactos medioambientales, incluyendo el controversial uso del cianuro para extraer el oro. Tocaremos en este trabajo esos temas del medio ambiente, pero el foco se centrará en un aspecto distinto de la disputa: el derecho del pueblo indígena de la zona a controlar el desarrollo en su territorio. Discutiremos el ejercicio del derecho indígena por la comunidad de Sipacapa, la aplicación de las leyes internas de Guatemala y la relevancia de normas internacionales como el Convenio sobre los Pueblos Indígenas y Tribales en los Países Independientes (Convenio 169), de la Organización Internacional del Trabajo (OIT). Observaremos el papel que han desempeñado el Banco Mundial y la embajada canadiense en el financiamiento y el apoyo a Glamis Gold. Y, finalmente, haremos algunas observaciones sobre la importancia de establecer un mecanismo independiente y efectivo de supervisión y control de las relaciones entre las industrias extractivas canadienses y los pueblos indígenas.

Con el fin de entender la peligrosa situación del pueblo indígena en la Guatemala de hoy día, resulta necesario revisar brevemente el pasado. Esta historia comienza con el golpe patrocinado por la CIA en 1954, y nos lleva a través del oscuro período de la guerra civil, cuando el gigante minero canadiense INCO estaba abriendo una mina en Guatemala. Durante y después de este período, el gobierno guatemalteco cometió genocidio contra grupos de la población maya. En 1985 se produjo la restauración de una frágil democracia, y en 1996 se firmó un acuerdo de paz con las guerrillas. La historia de Glamis Gold se inicia precisamente casi en el mismo momento en que se publicaba un informe del obispo José Gerardi sobre las brutalidades cometidas por el gobierno guatemalteco.

\section{LOS INTERESES EXTRANJEROS Y LA HISTORIA DE GUATEMALA}

La sociedad guatemalteca ha estado dominada históricamente por un pequeño grupo de descendientes de los colonizadores españoles, aliados siempre a los

\footnotetext{
${ }^{2}$ En uno de los primeros correos electrónicos enviados por Ladan desde San Marcos, la autora expresaba: "Por primera vez en mi vida me siento realmente avergonzada de ser canadiense".
} 
militares y los intereses foráneos. En 1951, cuando el presidente populista Jacobo Arbenz tomó posesión, inició una reforma agraria que hubiera expropiado las tierras ociosas de las empresas privadas para entregarlas a los campesinos $^{3}$. La poderosa United Fruit Company era una de esas empresas. A pesar de recibir una compensación apropiada, la United Fruit buscó la ayuda del gobierno norteamericano para impedir las reformas, acusando a Arbenz y su gobierno de ser comunistas ${ }^{4}$. Con el apoyo financiero y militar de la CIA, Castillo Armas invadió Guatemala desde Honduras en $1954^{5}$. El régimen de Armas favoreció la inversión extranjera y eliminó muchas de las beneficiosas reformas sociales que había iniciado Arbenz ${ }^{6}$.

La represión y las desigualdades económicas se hicieron más severas en los siguientes años, y nacieron ejércitos guerrilleros integrados en gran parte por indígenas. Una guerra civil comenzó en 1960. Fue una guerra feroz y desigual. Las guerrillas no podían enfrentar al ejército guatemalteco, armado y entrenado por Estados Unidos ${ }^{7}$. Más de 200,000 personas fueron asesinadas o quedaron desaparecidas, y un millón tuvo que abandonar sus lugares de residencia ${ }^{8}$. De los 42,275 actos de violencia registrados, el 85 por ciento fueron asesinatos cometidos por el ejército, bien actuando por su cuenta o en complicidad con otras fuerzas 9 . Una de las acciones más espantosas realizadas por el ejército fue una campaña para masacrar a los pobladores de las aldeas indígenas. Las atrocidades que se perpetraron durante esta campaña incluyeron la amputación de extremidades, el asesinato de niños, la quema de personas vivas y la extracción de órganos de víctimas aún con vida ${ }^{10}$.

${ }^{3}$ Laura Moye, "The United States Intervention in Guatemala" (1998) 73:1 y 2, International Social Science Review, pp. 44-45.

${ }^{4}$ Ibíd.

${ }^{5}$ Ibíd, p. 44.

${ }^{6}$ Ibíd.

${ }^{7}$ Andrew J. Schlewitz, "Imperial Incompetence and Guatemalan Militarism, 1931-1966" (2004) 17:4 International Journal of Politics, Culture and Society, pp. 585-600. Irónicamente, tanto Arbenz como Armas eran graduados de un programa de entrenamiento militar establecido por el gobierno norteamericano.

${ }^{8}$ Comisión de Esclarecimiento Histórico (CEH), "Guatemala: Memoria del Silencio"; en internet: http://shr.aaas.org/guatemala/ceh/mds/spanish/toc.html [CEH (1999)]; Patrick Ball, Paul Kobrak \& Herbert Spirer, "Violencia institucional en Guatemala, 1960-1996:

Una reflexión cuantitativa" (Washington, D.C.: American Association for the Advancement of Science, 1999); en internet: http://shr.aaas.org/guatemala/ciidh/qr/spanish/sp qr.pdf

${ }^{9}$ Informe de la CEH (1999), ibíd., en capitulo II, volumen 2, parafo 109, gráfica 6 http://shr.aaas.org/guatemala/ceh/mds/spanish/cap2/vol2/sint.html

${ }^{10}$ Ibíd. 
Las más serias violaciones de los derechos humanos se cometieron por parte del dictador Efraín Ríos Montt. Solo en 1982 ocurrieron 192 masacres $^{11}$. A pesar de su condena en 1983 de estas violaciones de los derechos humanos en Guatemala, al propio tiempo el gobierno canadiense negociaba la venta de aviones militares a la fuerza aérea de ese país ${ }^{12}$. Se conocía que los militares guatemaltecos empleaban sus aviones para ametrallar las aldeas indígenas ${ }^{13}$.

En 1983, el general Oscar Humberto Mejía Víctores derrocó a Ríos Montt y promovió el retorno a un sistema democrático en Guatemala ${ }^{14}$. El primer presidente civil en 15 años fue electo en $1985^{15}$. Sin embargo, los militares retuvieron aún mucho de su poder, y las masacres de los aldeanos indígenas continuaron hasta bien entrados los años $90^{16}$. Los militares también silenciaron a los críticos, entre ellos a la antropóloga Myrna Mack Chang, que se había dedicado a identificar los restos de los asesinados durante la guerra civil y a denunciar el papel de los militares en esas muertes. Mack Chang fue mortalmente apuñalada en $1990^{17}$.

En 1996 el gobierno y la guerrilla firmaron un acuerdo de paz, y por un momento hubo una promesa de significativa transformación de la sociedad guatemalteca. Según los términos del acuerdo, el gobierno estaría obligado a emprender acciones sobre un amplio rango de temas que incluían la reforma agraria y el desarrollo rural, la descentralización, las prestaciones sociales (salud, educación, empleo y seguridad social), la reforma del sistema de administración de justicia, la reforma de las fuerzas armadas y del sistema de inteligencia, la reforma electoral, el reconocimiento de los derechos de la

\footnotetext{
${ }^{11}$ Informe de la CEH (1999), nota 8; Ball, nota 8, pp. 21-22. Por ejemplo, Oliverio Castañeda de León, un miembro de la asociación de estudiantes de la universidad, fue ametrallado y muerto a plena luz del día ante cientos de testigos, incluyendo a la policía. Esta no hizo nada por perseguir o arrestar a los sicarios; Oficina de Derechos Humanos del Arzobispado de Guatemala (ODHAG), "Informe para la Recuperación de la Memoria Histórica: Nunca Más" (24 de abril, 1998), vol. 4, cap. 2; en internet: ODHAG http://www.odhag.org.gt/html/Default.htm [“Nunca Más"].

12 Jonathan Lemco, "Canadian Foreign Policy Interests in Central America: Some Current Issues” (1986) 28:2 J. Interamerican Studies and World Affairs, pp. 119-123.

${ }^{13}$ Ibíd.

${ }^{14}$ Susanne Jonas, The Battle for Guatemala: Rebels, Death Squads, and US Power (Boulder: Westview Press, 1991), p. 153.

${ }^{15}$ Ibíd., p. 156.

16 "Nunca Más", nota 11.

17 "International court condemns Guatemala over murder," Reuters News (19 de diciembre, 2003).
} 
mujer y la reincorporación de las poblaciones desplazadas durante la guerra civil $^{18}$.

Particularmente importante fue el Acuerdo sobre la Identidad y los Derechos de los Pueblos Indígenas ${ }^{19}$, que establecía derechos políticos para el pueblo maya al redefinir a Guatemala como una nación multiétnica, multicultural y plurilingüe ${ }^{20}$. Este acuerdo se pronunciaba también por el reconocimiento constitucional y legal de las formas organizativas, las prácticas políticas y el derecho consuetudinario de los mayas. En lo que respecta a los derechos culturales el acuerdo se centraba en la lengua y la "autodeterminación" cultural, y pedía la creación de instituciones representativas que defendieran y fortalecieran la cultura maya, así como la oficialización de todas sus lenguas. La sección referente a los derechos económicos hacía hincapié en el problema de la tierra, y reclamaba la restitución de todas las tierras comunales expropiadas, la titularización inmediata de las tierras ocupadas históricamente por el pueblo maya, y un amplio programa de reforma agraria ${ }^{21}$. El acuerdo creaba la base formal para un nuevo posicionamiento jurídico de la mayoría indígena, otorgándole el derecho a presentar sus demandas ante el Estado.

Se iniciaron dos investigaciones sobre los abusos cometidos durante la guerra. En 1998 el obispo Juan José Gerardi dio a conocer un número de evidencias, así como los testimonios de 600 personas, recogidos en toda Guatemala a lo largo de tres años. Su informe, "Guatemala: Nunca Más", atestaba que en el transcurso de la guerra civil fueron asesinadas 150,000 personas, 50,000 desaparecieron y un millón tuvo que desplazarse $\mathrm{e}^{22}$. Dos días después de la publicación de este informe, el obispo Gerardi fue golpeado hasta la muerte en el exterior de su vivienda ${ }^{23}$. Al principio la policía y el

18 Luis Pásara, "The Guatemalan Peace Process: The Accords and Their Accomplishments", Kroc Institute Occasional Paper (diciembre de 2001), p. 12.

${ }^{19}$ Acuerdo sobre la identidad y los derechos de los pueblos indígenas; en internet: http://www.congreso.gob.gt/Docs/PAZ/Acuerdo\%20sobre\%20identidad\%20y\%20derechos $\% 20 \mathrm{de} \% 201$ os\%20pueblos\%20ind\%C3\%ADgenas.pdf

${ }^{20}$ Hilde Salvesen, "Guatemala: Five Years after the Peace Accords" (Oslo: International Peace Research Institute [PRIO], marzo de 2002); en internet: PRIO http://www.prio.no/files/file44990 guatemala report salvesen.pdf

${ }^{21}$ Rachel Sieder, "Reframing Citizenship: Indigenous Rights, Local Power and the Peace Process in Guatemala" (1997); en internet: Conciliation Resources http://www.c-r.org/ourwork/accord/guatemala/reframing-citizenship.php

${ }^{22}$ Teo Ballve, "Remembering in the Land that Memory Forgot", NACLA News (14 de mayo, 2007); en internet: North America Congress on Latin America (NACLA) http://news.nacla.org/2007/05/14/remembering-in-the-land-that-memory-forgot/

${ }^{23}$ Rachel Sieder, "Coming to Terms with the Past: Remembering and Forgetting in Guatemala", History Today 55: 9 (septiembre 2005), pp. 28-29. 
gobierno trataron de catalogar el suceso como un intento de robo, luego como una pelea doméstica, y por último como un ataque por un perro. Tras un esfuerzo concertado de la Iglesia Católica y varias agencias internacionales, se presentaron cargos contra individuos relacionados con el ejército ${ }^{24}$. Hubo amenazas de muerte contra testigos y otras personas conectadas con el proceso, y en 2001 tanto el fiscal, Leopoldo Zeissig, como la jueza que llevaba el juicio, Yasmín Barrios, se vieron obligados a abandonar el país ${ }^{25}$.

La promesa de reformas a la Constitución, que brindarían un mayor reconocimiento a las comunidades indígenas, jamás se hizo realidad. La ONU había desempeñado un importante papel en lograr que se reconocieran los derechos del pueblo indígena, pero la élite dirigente continuó siendo hostil y no promovió ningún cambio en el texto constitucional. Un referendo sobre la reforma fue derrotado en 1999, tras una virulenta campaña en contra organizada por elementos del sector privado ${ }^{26}$.

Ese mismo año la Comisión de Esclarecimiento Histórico (CEH), patrocinada por la ONU, publicó su informe, "Guatemala: Memoria del Silencio" "27. La CEH encontró que el Estado había sido responsable del 93 por ciento de las violaciones de derechos humanos ocurridas durante la guerra ${ }^{28}, \mathrm{y}$ que había "cometido actos de genocidio contra grupos del pueblo maya"29.

\section{EL PROYECTO MARLIN}

Pocos meses después del asesinato del obispo Gerardi apareció en Guatemala Glamis Gold ${ }^{30}$. La subsidiaria de Glamis, Montana Exploradora, recibió del

\footnotetext{
${ }^{24}$ Amnistía Internacional, El Legado Mortal de Guatemala (2002), pp. 32-37; en internet: Amnistía Internacional http://www.amnistiainternacional.org/publica/

ISBN_8486874785.html [Legado Mortal]

25 "Guatemala lawyer flees death threats", BBC News (30 de julio, 2001); en internet: BBC News http://news.bbc.co.uk/2/hi/americas/1465512.stm

${ }^{26}$ Véase Rachel Sieder, "The Judiciary and Indigenous Rights in Guatemala" (2007) 5:2, International Journal of Constitutional Law, p. 219.

${ }^{27}$ Naciones Unidas, "Informe de la Misión de Verificación de Naciones Unidas en Guatemala (MINIGUA), para la reunión del Grupo Consultivo para Guatemala" (18 de enero de 2002), p. 2; en internet: Banco Interamericano de Desarrollo http://www.iadb.org/regions/re2/consultative_group/gu/minugua_esp.pdf

${ }^{28}$ Ibíd., párr. 6.

${ }^{29}$ Ibíd.

${ }^{30}$ Informe de la Oficina del Asesor en Cumplimiento/Ombudsman [CAO, según las siglas de su nombre en inglés: Compliance Advisor/Ombudsman]: "Evaluación de una reclamación presentada a la CAO en relación con el Proyecto Minero Marlin en Guatemala (7 de septiembre, 2005); en internet: CAO, http://www.cao-
} 
Ministerio de Energía y Minas, en agosto de 1999, una licencia de exploración inicial para la mina Marlin ${ }^{31}$.

Las regiones afectadas por el proyecto Marlin son las de San Miguel Ixtahuacán y Sipacapa, ambas en el Departamento de San Marcos. Estas comunidades están principalmente integradas por indígenas mayas, que además del español hablan sus lenguas tradicionales.

Glamis comenzó por reunirse con las autoridades municipales de ambos lugares en $2002 .^{32}$ En el curso de sus trabajos de exploración, la compañía realizó 30 reuniones en San Miguel Ixtahuacán y 17 en Sipacapa, entre junio y septiembre de 2003. De acuerdo con Glamis, en estas reuniones se trataron temas medioambientales, entre otros de interés para las respectivas comunidades. Más tarde en ese mismo año, Glamis recibió una licencia de explotación por 25 años para el proyecto Marlin, y otra de exploración para el área Marlin I. Pocos meses más tarde, también recibió del Ministerio de Energía y Minas otra licencia de exploración, esta para el área Marlin II. La construcción de la mina se inició en mayo de $2004 .{ }^{33}$ Al siguiente mes, el proyecto Marlin se benefició, a través de la Corporación Financiera Internacional (CFI), de un préstamo por valor de $\$ 45$ millones de dólares. ${ }^{34} \mathrm{La}$ CFI, que forma parte del Banco Mundial, hace préstamos a compañías del sector privado para proyectos en los países en desarrollo. El propósito de este financiamiento es fomentar la creación de mercados competitivos en esos países, a la vez que se promueve la mejoría en las condiciones de vida de sus pueblos ${ }^{35}$.

Con el fin de adquirir las tierras que requería para el proyecto Marlin, Glamis se las compró a propietarios individuales. Aparentemente, estas transacciones se hicieron con 254 propietarios, y todas tuvieron como testigos a funcionarios municipales. En aquel momento Glamis dijo que no se había presentado queja alguna con respecto a ellas, y que todas se realizaron

ombudsman.org/cases/document-links/documents/CAO-Marlin-evaluacion-final-8sept05.pdf [Informe de la CAO (2005)].

${ }^{31}$ Ibíd.

${ }^{32}$ Anexos al Informe de la CAO (2005), nota 30, p.17, en internet: CAO http://www.caoombudsman.org/cases/document-links/documents/CAO-Marlin-evaluacionanexos-final8sept-05.pdf [“Anexos al Informe de la CAO (2005)"].

${ }^{33}$ Ibíd., p. 21.

34 "Montana Exploradora: Marlin Gold Project"; en internet: The World Bank http://siteresources.worldbank.org/INTOGMC/Resources/marlinfactsheetenglish.pdf, p. 1 [“Marlin Fact Sheet"].

35 "Acerca de la CFI"; en internet: International Finance Corporation http://www.ifc.org/about 
exitosamente $^{36}$. La compañía informó que había abonado 4,000 quetzales por cuerda ( $\$ 4,567$ dólares norteamericanos por acre) a cada propietario, por tierras que usualmente se venden a un precio de entre 350 y 1,500 quetzales por cuerda ${ }^{37}$. Igualmente argumentó que el ingreso anual promedio en Guatemala es de \$1,670 dólares norteamericanos, de manera que sus compras ponían verdaderas "fortunas" en manos de los vendedores ${ }^{38}$.

\section{LA DECISIÓN DEL PUEBLO INDÍGENA DE SIPACAPA}

Ambos municipios, Sipacapa y San Miguel Ixtahuacán, están afectados por la mina, pero el 85 por ciento de la instalación se encuentra en el segundo. Y aunque hubo oposición a la actividad minera en ambos lugares, solo el concejo municipal de Sipacapa decidió llevar a votación el asunto.

Hay 13 aldeas en el municipio de Sipacapa. La estructura de gobierno de cada aldea comprende una asamblea comunitaria, un consejo de desarrollo y un alcalde auxiliar electo. Existe un organismo municipal más amplio, que incluye a representantes de todas las aldeas y está encabezado por un alcalde municipal $^{39}$. Los habitantes de Sipacapa hablan sipacapense, un lenguaje diferente al mam hablado por sus vecinos de San Miguel Ixtahuacán. La mayoría de los pobladores de ambos municipios son campesinos de subsistencia.

El tema de la mina había sido objeto de controversia por algún tiempo, con protestas que se iniciaron en Sipacapa en febrero de $2004^{40}$. Los residentes estaban preocupados por el impacto medioambiental de la mina, pero también por la actividad minera como un factor de desarrollo, y favorecían propuestas alternativas controladas por la comunidad ${ }^{41}$. Una encuesta realizada en el Departamento de San Marcos, y que se dio a conocer el 4 de noviembre de 2004, mostró que 95,5\% de los encuestados estaba en desacuerdo con la implementación del proyecto minero, debido a los temores de que dañara el

\footnotetext{
${ }^{36}$ Informe de la CAO (2005), nota 30, p. 26.

${ }^{37}$ Montana Exploradora de Guatemala S.A., "Marlin Mining Project Land Acquisition Procedures" $(20$ de febrero de 2004); en internet: Goldcorp Inc. http://www.goldcorp.com/_resources/_project_pdfs/marlin/landacq.pdf, p. 3.

${ }^{38}$ Ibíd.

${ }^{39}$ Informe de la CAO (2005), nota 30, p. 6.

${ }^{40}$ Anexo al Informe de la CAO (2005), nota 32, p. 21.

41 "Declaración de las organizaciones de la sociedad civil sobre la mina Marlin, financiada por la CFI en Guatemala" (12 de junio de 2006); en internet: Bank Information Center http://www.bicusa.org/Legacy/Statement\%20on\%20Marlin\%20-\%20June\%202006.pdf
} 
medioambiente ${ }^{42}$. El 6 de noviembre, en una reunión que se celebró en Sipacapa, se emitió un pronunciamiento que señalaba, entre otras cosas:

Declaramos públicamente, a nivel nacional e internacional, que la concesión de una licencia para explotar una mina a cielo abierto viola los derechos colectivos de los pueblos indígenas que habitan nuestros territorios ${ }^{43}$.

En diciembre, un grupo de indígenas que vivían a 150 kilómetros de la mina, en Sololá, inició un bloqueo del camino por donde pasaban los camiones de Glamis hacia San Marcos. El bloqueo, que se prolongó por 42 días, terminó el 11 de enero de 2005, cuando más de 1,200 soldados y 400 policías comenzaron a disparar contra los desarmados manifestantes. Raúl Castro Bocel, un campesino indígena, fue ultimado por las fuerzas de seguridad, y otros veinte participantes en la protesta resultaron heridos ${ }^{44}$. Glamis achacó las protestas a la desinformación propalada por los activistas anti-minería ${ }^{45}$. Pocas semanas más tarde, el obispo católico Álvaro Ramazzini lideró una protesta de 3,000 personas en San Marcos, donde estaba localizada la mina ${ }^{46}$. El 24 de enero de 2005 las comunidades de Sipacapa decidieron actuar. El concejo municipal aprobó la primera de tres resoluciones que establecían una Consulta

42 Prensa Libre, "Rechazan actividad minera en San Marcos: Habitantes de dos municipios señalan que explotación causará daños al medio ambiente" (4 de noviembre de 2004); en internet: Prensa Libre: http://www.prensalibre.com/pl/2004/ noviembre/04/100844.html

${ }^{43}$ Declaración Comunitaria sobre la Licencia de Minería de Metales a Cielo Abierto en el Departamento de San Marcos (6 de noviembre de 2004). La declaración llevaba los cuños de 35 organizaciones, cerca de 80 firmas, y una docena de impresiones dactilares de personas que no sabían escribir.

${ }^{44}$ Mining Watch, "Mayan Organisations and Supporters Demand the Closure of the Marlin Mine in San Marcos, Guatemala"; en internet: Mining Watch http://www.miningwatch.ca/ index.php?/Guatemala/Close Marlin; Julio Lara, Edgar René Sáenz, "Queman autopatrulla - Vecinos de Sololá atacan Policía durante cortejo de muerto en disturbios" (13 de enero de 2005); en internet: Prensa Libre http://www.prensalibre.com/pl/2005/enero/13/105397.html "Open Pit Gold Mining: Human Rights Violations and Environmental Destruction - The Case of the Marlin Gold Mine", FoodFirst Information and Action Network (FIAN) (septiembre 2005), p. 3.

${ }^{45}$ Nota de Prensa de Glamis Gold, "Glamis Gold Comments on Transport Incident" (13 de enero de 2005); en internet: Goldcorp Inc. http://www.goldcorp.com/_resources/glamis/pressreleases/2005/ jan13-05.pdf

${ }_{46}$ Kelly Patterson, "Canadian Mine Strikes Lode of Unrest: The Debate over the Presence of a Gold Mine in Guatemala has Resulted in a Call for 'Urgent Action' by Amnesty International", Ottawa Citizen (26 de abril de 2005). 
de Buena $\mathrm{Fe}^{47}$. El proceso daría una oportunidad "para que las autoridades indígenas, la población indígena de ascendencia maya sipacapense y vecinos mayores de 18 años del municipio Sipacapa se pronunciaran a favor o en contra de la actividad minera de reconocimiento, exploración y explotación de minerales metálicos a cielo abierto en dicho municipio" ${ }^{48}$. Se creó una comisión integrada por miembros de las estructuras de gobierno de la aldea, y del concejo municipal, con el fin de que organizara y diera a conocer el resultado de la consulta. La decisión sería "de observancia general y obligatoria en el territorio del municipio"49.

En la tarde del domingo 13 de marzo de 2005 se celebraba un concierto coral en la iglesia de la parroquia de San Miguel Ixtahuacán, departamento de San Marcos. Álvaro Benigno, un hombre de la aldea de Pie de la Cuesta, en Sipacapa, asistía al concierto. De acuerdo con testigos oculares, cuando abandonaba la iglesia para regresar a su hogar, dos agentes del Grupo Golan, una compañía privada de seguridad contratada por Glamis, le hicieron cinco o seis disparos. Benigno fue llevado al hospital de Huehuetenango, donde se certificó su fallecimiento ${ }^{50}$. Según Glamis, el incidente había sido una disputa privada, y en una nota de prensa informó que la compañía se había reunido con la familia del fallecido para asesorarla en la acusación contra los guardias de la agencia privada de seguridad ${ }^{51}$.

El 8 de junio, diez días antes de la consulta, Glamis dio a conocer una nota de prensa que hacía ver al proceso como algo siniestro, intimidante y lleno de secretismo:

\footnotetext{
${ }^{47}$ Actas 04-2005 de 24 de enero, 06-2005 de 7 de febrero, 09-2005 de 28 de febrero, Corte de Constitucionalidad, Guatemala, "Caso Sipacapa (Minerías)", Expediente 1179 - 2005, (8 de mayo de 2007), p. 2; en internet: Corte de Constitucionalidad de Guatemala http://www.cc.gob.gt/index-2.html. Este enlace ya no funciona y no se encuentra el caso en el sitio de la corte. El documento consta en los archivos del autor.

${ }^{48}$ Ibíd., p. 1.

${ }^{49}$ Ibíd., p. 21.

${ }^{50}$ Mining Watch, "Killing of Álvaro Benigno Sánchez by Security Guards Working for Glamis Gold Subsidiary in Guatemala" (5 de abril de 2005); en internet: Mining Watch http://www.miningwatch.ca/index.php?/Guatemala/Killing_of_Alvaro_Be Hasta el presente nadie ha sido encausado por estos crímenes. De acuerdo con Álvaro Sánchez, padre del fallecido, y varias ONG que trabajan en Guatemala, el gerente del Grupo Golan telefoneó en varias oportunidades a la familia de Benigno para ofrecerle un "arreglo" monetario con el fin de asegurar que no iniciara un proceso legal contra la compañía.

${ }^{51}$ Véase la nota de prensa de Glamis Gold, "Glamis Gold Comments on Recent Events in Guatemala" (20 de abril de 2005); en internet: Goldcorp Inc.

http://www.goldcorp.com/_resources/glamis/press releases/2005/apr20-05.pdf
} 
Glamis ha conocido que un pequeño grupo de individuos de Sipacapa está proponiendo celebrar un referendo sobre si el municipio quiere o no un futuro desarrollo mineral en su territorio... La información obtenida hasta el momento proviene de varias fuentes dignas de crédito.

Glamis ha recibido informes de intimidación por parte de los organizadores del referendo, incluyendo amenazas de cortar el suministro de agua o quemar las cosechas de los residentes si votan contra el referendo. La compañía entiende que no habrá voto secreto, sino que mediante esas amenazas e intimidaciones los organizadores del referendo pretenden realizar un voto público a mano alzada ${ }^{52}$.

Glamis "comunicaba su preocupación" a las organizaciones no gubernamentales que apoyaban a los habitantes de Sipacapa, ante este "proceso aparentemente antidemocrático y abusivo", y les sugería que reconsideraran su posición. Glamis catalogaba el referendo de "patentemente corrupto". Este era un lenguaje fuerte y, en el contexto de Guatemala, amenazante $^{53}$.

La comunidad había coordinado que un grupo de 70 observadores nacionales e internacionales estuviera presente antes, durante y después de la Consulta. En América Latina se suele convocar a los observadores internacionales con el fin de asegurar alguna protección a los pueblos indígenas en el transcurso de los conflictos en torno a la extracción de recursos. La presencia de observadores actúa como contención al uso de la fuerza. Se comprende entonces que Glamis considerara su presencia como negativa, refiriéndose oscuramente a ellos como "grupos de presión" 54 .

Ladan Mehranvar formaba parte de estos observadores internacionales ${ }^{55}$. Ella realizó entrevistas en la comunidad para determinar la fuente de las informaciones acerca de la intimidación de las personas por los activistas antiminería, pero no logró hallar ninguna evidencia que no fueran los rumores reportados por Glamis. La policía local declaró que no había recibido ninguna denuncia de amenazas, ni conocido de ninguno de tales incidentes.

\footnotetext{
${ }^{52}$ Nota de prensa de Glamis, "Glamis Gold Comments on Proposed Referendum in Guatemala" (8 de junio de 2005); en internet: Goldcorp Inc. http://www.goldcorp.com/_resources/glamis/press releases/2005/jun8-05.pdf ${ }_{53}$ Ibíd. Glamis alegaba que la mayoría de los pobladores del área apoyaba a la mina.

${ }^{54}$ Ibíd. Estos grupos incluían a simpatizantes guatemaltecos como el grupo ecologista Madre Selva y la Iglesia Católica. Había también algunas ONG internacionales, como CARE y Rights Action.

${ }^{55}$ La descripción del desarrollo de la Consulta se basa en sus propias observaciones.
} 
El 13 de junio, cinco días antes de la votación, Glamis procuró una orden judicial para impedir la celebración de la consulta. Como resultado, el juez emitió al efecto un mandato provisional ${ }^{56}$. La municipalidad apeló esta decisión el 17 de junio ante la Corte de Constitucionalidad, pero el alcalde decidió retirar su apoyo a la consulta. Casi al mismo tiempo, el Ministerio de Energía y Minas se había dirigido directamente a la Corte, que no emitió una requisitoria. No obstante, las comunidades prosiguieron con sus planes para la votación, y se hizo una convocatoria por la radio.

El día anterior a la consulta, algunos niños de la comunidad distribuyeron panfletos anónimos que pedían que el proceso fuese cancelado. Similares peticiones se hicieron a través de las estaciones de radio locales. Posteriormente se descubrió que los panfletos habían salido de las oficinas de Montana Exploradora, la subsidiaria de Glamis.

Pese a todos los intentos por impedirla, la consulta se celebró al mismo tiempo en tres lugares dentro del pueblo de Sipacapa y en 10 comunidades rurales de la región. Cada comunidad se reunió en su centro comunitario, con bancos y sillas colocados en varias filas frente a un estrado. En las tres comunidades visitadas por Ladan hablaron el alcalde auxiliar y otros dirigentes locales. Cada centro comunitario estaba conectado con la estación local de radio, que transmitía el evento en vivo, asegurando así un voto simultáneo. La pregunta que se hacía a las comunidades era: “¿Está usted a favor de la actividad minera en el territorio del pueblo sipacapense?"

Cada comunidad llevó a cabo su votación de acuerdo con las tradiciones y costumbres de cada una de ellas en particular. Así, en algunas hubo un voto directo a mano alzada. Este fue el caso en San Isidro. El grupo incluía a mujeres con sus niños en brazos y montones de muchachos. A los participantes se les daba la oportunidad de hablar, y entonces cinco o seis dirigentes comunitarios, incluyendo al alcalde mayor, contaban dos veces las manos levantadas. En la comunidad de Sipacapa el voto se realizó mediante boletas secretas. En otras, como las de Quecá y Chual, la gente hacía cola y marcaba individualmente su voto (sí o no) en un gran papel (el "Acta") que era llevado por el alcalde auxiliar de la comunidad. Los votantes que no sabían firmar estampaban en el Acta las huellas de sus pulgares.

Los observadores nacionales e internacionales se organizaron en pequeños grupos para asegurar un voto transparente. Cada grupo tenía también la tarea de llevar un registro de todos los eventos ocurridos durante la consulta en la

\footnotetext{
${ }^{56}$ Lic. Guillermo Galindo González, Juez Séptimo de Primera Instancia Civil, Proceso Constitucional de Amparo 87-2005 (13 de junio de 2005).
} 
comunidad a la que había sido asignado, incluyendo la respuesta de un cuestionario elaborado por los organizadores del referendo. Los observadores informaron que hubo un alto nivel de participación, tanto de hombres como de mujeres, y que no se produjeron incidentes de violencia o coerción.

En total, 2,426 personas votaron contra el proyecto minero, 35 a favor, 8 boletas eran ilegibles, una estaba en blanco, y 32 votantes se abstuvieron. De las 13 asambleas comunitarias, 11 rechazaron el proyecto (la gran mayoría por unanimidad), una lo apoyó, y otra se abstuvo. En total, 98,5\% de los votantes rechazaron la actividad minera. El número de participantes en el referendo fue de 2,502. Del total de personas con derecho al voto en Sipacapa, este número representa el 44,3\%. Como antecedente, en las elecciones nacionales de 2004 participaron en Sipacapa 3,087 personas, es decir 54,6\% de la población electoral.

El 21 de junio de 2005 la población sipacapense y cada alcalde auxiliar de las comunidades se reunieron en la plaza central de Sipacapa, San Marcos, para presentar a las autoridades municipales los resultados de las consultas comunitarias. El concejo municipal emitió un acuerdo que en su parte dispositiva señala: "Acuerda: Atenerse al resultado de la Consulta Comunitaria llevada a cabo el 18 de junio de 2005 por las autoridades comunitarias de las aldeas de la municipalidad de Sipacapa, San Marcos." De esta manera se confirmaba la decisión de los ciudadanos de rechazar la exploración, la explotación y la extracción de minerales en el territorio del pueblo sipacapense ${ }^{57}$.

Todos estos acontecimientos ocurrieron contra un trasfondo de violencia inminente y real.

El obispo Ramazzini, que había encabezado la marcha contra la mina, comenzó a recibir amenazas de muerte y tuvo que pedir la protección gubernamental ${ }^{58}$. También recibieron amenazas de muerte otros activistas anti-minería, y el auto de uno de ellos fue incendiado ${ }^{59}$. Después de que los miembros del grupo ecologista Madre Selva recibieran amenazas y ataques, la Comisión Interamericana de Derechos Humanos ordenó al gobierno darles

\footnotetext{
${ }^{57}$ Mines \& Communities, "The People of Sipacapa Reject Mining Activities in their Territory: We Demand that Their Sovereign Decision be Respected"; en internet: Mines and Communities: http://www.minesandcommunities.org/Action/press667.htm

${ }^{58}$ Patterson, nota 46.

${ }^{59}$ Ibíd.
} 
protección policial $^{60}$. Glamis dijo que sus trabajadores también fueron amenazados. Lo que resulta interesante es la opinión sobre estas amenazas de muerte que tenía Kevin McArthur, entonces director general de la compañía. Una nota de prensa de Glamis, publicada el 23 de junio de 2005, describía de esta forma un incidente en Sololá:

Tres residentes del municipio de Sololá (aproximadamente a $20 \mathrm{~km}$ del proyecto Marlin) supuestamente recibieron amenazas de muerte por su oposición a la minería en general y al proyecto Marlin en particular. Esto coincide con las amenazas de muerte y las amenazas de violencia que se han dirigido contra los empleados y el personal contratado de Marlin en meses recientes ${ }^{61}$.

La nota de prensa sugería que, en opinión de Glamis, las amenazas de muerte contra los activistas anti-minería eran solo suposiciones, mientras que las lanzadas contra los empleados de la compañía eran un hecho. McArthur condenó la violencia y declaró que Glamis no tenía conocimiento de las personas que realizaban tales acciones. Sin embargo, en ninguna de las notas de prensa emitidas en aquel tiempo por Glamis hay indicaciones de que la empresa investigara las amenazas contra los activistas o que tuviera alguna política para manejar dicha situación ${ }^{62}$.

\section{V. ¿EJERCICIO DEL DERECHO INDÍGENA, O EJERCICIO DE LA LEY GUATEMALTECA POR EL PUEBLO INDÍGENA?}

Con anterioridad a los años 1990 el criterio que prevalecía en los círculos legales y políticos era que solo las leyes sancionadas por el Estado eran válidas, y que las que aplicaban los pueblos indígenas no eran en lo absoluto leyes, sino únicamente costumbres, tradiciones, hábitos o instintos. Este era el enfoque que permitió a un tribunal australiano, en 1971, declarar que en materia de derecho Australia era terra nullius ("tierra de nadie") cuando

\footnotetext{
${ }^{60}$ Amnistía Internacional, "Guatemala: Further Information on Fear for Safety: Flaviano Bianchini (m)" (23 de febrero de 2007); en internet: Amnesty International, Urgent Actions http://web.amnesty.org/library/Index/ENGAMR340092007?open\&of=ENG-GTM ["Fear for Safety"].

${ }^{61}$ Nota de prensa de Glamis Gold, "Glamis Gold Comments on Sipacapa Referendum” (23 de junio de 2005); en internet : Goldcorp Inc.

http://www.goldcorp.com/_resources/glamis/pressreleases/2005/jun23-05.pdf

${ }^{62}$ Informe de la CAO (2005), nota 30, p. 36. "No se ha establecido ningún sistema para enfrentar las denuncias sobre amenazas a la seguridad."
} 
llegaron los primeros colonos. En otras palabras, que los aborígenes no existían porque no tenían "ley" ${ }^{63}$. En 1990, el magistrado canadiense McEachern emitió una decisión similar, sobre la base de que, al no poseer las mismas instituciones, estructuras gubernamentales o conocimientos tecnológicos, las sociedades de las naciones originarias de Canadá no tenían ley, orden social o humanidad:

Ni por asomo resultaría correcto asumir que la existencia pre-contacto en el territorio era idílica. Los antepasados del demandante no tenían lenguaje escrito, ni caballos o vehículos rodantes; la esclavitud y el hambre eran comunes, las guerras con los pueblos vecinos frecuentes, y no hay duda, para citar a Hobbes, de que la vida [aborigen] en el territorio era, en el mejor de los casos, "desagradable, salvaje y breve",

El juez concluía que "[los habitantes de las naciones originarias] probablemente actuaban como lo hacían, solo en respuesta a instintos de supervivencia" $" 65$.

No hay duda de que tales enfoques ya no son permisibles. Las leyes indígenas han sido aceptadas en sus propios términos, tanto en la esfera doméstica como en la internacional ${ }^{66}$. Lo que está en discusión no es si el derecho indígena existe, sino cómo este derecho interactúa con la legislación estatal.

De manera que es importante analizar desde esta perspectiva lo que ocurrió con la consulta en Sipacapa. Hay tres aspectos que deben resaltarse:

Primero, la decisión de celebrar la consulta no la tomaron "individuos privados", como alegaba Glamis, sino que se canalizó a través de las estructuras de gobierno existentes en la comunidad. La municipalidad aprobó debidamente tres resoluciones relativas al proceso, que fueron implementadas por las estructuras de gobierno en las aldeas.

Segundo, hubo un proceso transparente, que se realizó mediante reuniones comunitarias anunciadas con antelación. El día de la consulta las deliberaciones estuvieron bien organizadas, se celebraron con orden y

\footnotetext{
${ }^{63}$ Caso Milirrpum v. Nabalco Pty Ltd. (1971), 17 Family Law Report 141.

${ }^{64}$ Esta decisión del magistrado McEachern se emitió en el Caso Delgamuukw v. British Columbia, [1991] 5 Canadian Native Law Reporter. 1, párr.111. La Corte Suprema de Canadá rechazó firmemente los comentarios de McEachern, revocó la sentencia y ordenó en 1997 un nuevo juicio sobre el caso: [1997] 3 Supreme Court Reporter 1010.

${ }^{65}$ Ibíd., párr. 1343, McEachern Chief Justice of British Columbia.

${ }^{66}$ Véase, de manera general, S. James Anaya, Indigenous Peoples in International Law, 2da. ed. (Oxford: Oxford University Press, 2004).
} 
brindaron los medios para que los miembros de la comunidad expresaran sus deseos. El hecho de que una comunidad se abstuviera, y otra decidiera votar a favor de la mina, indica que el proceso comprendió un amplio espectro de resultados diferentes.

Tercero, la consulta, y el efecto vinculante que se pretendía que tuviera, fueron una enfática expresión de la voluntad comunitaria. La comunidad tenía derecho a realizar la consulta, y derecho a obligar al gobierno y a la compañía minera a respetar el resultado en su territorio. De acuerdo con el derecho indígena, la comunidad podía decidir si debía haber o no actividad minera en su territorio ${ }^{67}$.

Desde el punto de vista de los indígenas, la autoridad y la jurisdicción para actuar no emanan de la legislación guatemalteca. La autoridad emana de los derechos inherentes que acompañan al hecho de ser un pueblo indígena. La resolución de la municipalidad que se mencionó más arriba habla de la "decisión soberana de la voluntad de la población indígena y no indígena" El hecho de que un juez intentara dictar una prohibición no era válido en el contexto del derecho indígena, y fue por ello que el proceso de consulta prosiguió a pesar de esa decisión judicial. La comunidad enfatizó este punto a un representante del panel asesor del Banco Mundial, que fue a Sipacapa en mayo de 2006 para tratar de que se iniciara un diálogo entre la comunidad y Glamis:

[El criterio de los miembros de la comunidad] es que el referendo popular que se realizó el 18 de junio de 2005 ha puesto fin a la discusión sobre la minería, y su posición es clara: "no queremos actividades mineras en nuestro territorio". También señalaron la importancia de conservar sus tierras y no venderlas a la compañía. Si bien algunos miembros de la comunidad desean proseguir el debate sobre minería, la mayoría no tiene interés en seguir discutiendo la cuestión ni en entablar un diálogo sobre el tema. La frase "podemos ignorar la mina mientras no nos afecte" sintetiza la actitud prevaleciente. No obstante, existe poca aceptación de la mina y no se han resuelto las raíces de la controversia ${ }^{69}$.

\footnotetext{
${ }^{67}$ Informe de la CAO (2005), nota 30, p. 31.

${ }^{68}$ Corte, nota 62, p. 20

${ }^{69}$ Oficina del Ombudsman y Asesor (CAO), del Banco Mundial: "Seguimiento del Informe de la CAO sobre Guatemala (mayo de 2006); en internet: CAO, http://www.caoombudsman.org/cases/document-links/documents/CAOMarlin_Report espanol-

3 _Mayo 06.pdf, p. 7.
} 
La mina desafió los resultados de la consulta y admitió abiertamente que continuaba explorando la tierra en Sipacapa, a despecho de la opinión de los dirigentes municipales ${ }^{70}$. Según Glamis, se realizaban actividades de exploración solo en las comunidades donde se recibía apoyo y consentimiento expresos $^{71}$. Desde el punto de vista del derecho indígena, esto constituía una evidente violación. Los líderes de la comunidad habían dicho que no se debía vender ninguna tierra a la mina, y si bien cualquier persona en Sipacapa tenía derecho a vender su tierra, esto debía determinarse por la comunidad y no por la mina. Si en Canadá hubiera una ley que prohibiera la venta de agua, y una compañía norteamericana intentara comprársela directamente a "vendedores dispuestos a hacerlo", tal acto sería ilegal, con independencia de los deseos de los individuos.

Esto no quiere decir que exista consenso en cuanto a que la ley estatal deba acceder automáticamente cuando entre en conflicto con la ley indígena. Lo que sí está claro es que la relación entre derecho indígena y derecho estatal se está resolviendo actualmente tanto en la arena doméstica como en la internacional. En la presenta etapa, tanto el derecho doméstico como el internacional han establecido restricciones para los actores no indígenas que violen el derecho indígena. Estas restricciones previenen el desconocimiento unilateral del derecho indígena. Desde la perspectiva de este último, no obstante, resulta imprescindible comprender que dichas restricciones son impuestas sobre actores no indígenas por actores no indígenas, y que no deben confundirse con el derecho indígena en sí.

A fin de entender cómo funcionaron tales restricciones en el caso objeto del presente estudio, es importante apreciar los desequilibrios de poder que constituyen una realidad para el pueblo indígena en Sipacapa y San Miguel Ixtahuacán.

\footnotetext{
${ }^{70}$ Ibíd., p.8: “... la mina sigue negociando con los terratenientes en forma individual para explorar posibles yacimientos de mineral en Sipacapa, y por lo menos algunos miembros de la comunidad están al tanto de estas actividades... Si bien entendemos que no se han adquirido tierras adicionales, la mina está llevando a cabo actividades de exploración con autorización de algunos terratenientes y aldeas, pero sin la expresa aprobación del municipio".

${ }^{71}$ Glamis Gold, Respuesta al Informe de Seguimiento de la CAO ("Response to CAO Follow-up Assessment Report"), 22 de mayo de 2006. (El documento consta en los archivos del autor).
} 


\section{DESEQUILIBRIO DEL PODER}

Goldcorp posee activos por valor de $\$ 17,9$ mil millones de dólares norteamericanos $^{72}$. Esto constituye más de la mitad del PIB de Guatemala, que es de $\$ 35,25$ mil millones ${ }^{73}$. La compañía es "el mayor contribuyente que ha habido jamás en Guatemala" ${ }^{94}$, y afirma que contribuirá con $\$ 69,9$ millones de dólares en impuestos y regalías al gobierno guatemalteco durante once años ${ }^{75}$.

Los enormes recursos financieros de la minera fueron públicamente reconocidos por el gobierno de Guatemala. Una nota de prensa de Glamis, del 8 de septiembre de 2005, hace un entusiasta reporte del anuncio de una nueva carretera en San Marcos, e incluye las palabras del presidente Oscar Berger: "San Miguel va a ganar nuevos empleos, actividad económica e infraestructura... Este es un proyecto ejemplar" ${ }^{\text {"76. }}$.

En adición, la mina estaba involucrada en diversos proyectos a nivel local. Glamis/Montana creó su propia "ONG", denominada Fundación Sierra Madre, que trabaja con la ONG norteamericana Citizens Development Corps. De acuerdo con sus informes, la fundación tiene comadronas entrenadas, ofrece entrenamiento vocacional en carpintería, costura y cocina, posee centros de salud acondicionados y estableció 18 bancos comunales para mujeres ${ }^{77}$. Para septiembre de 2005 Glamis había invertido \$1,3 millones de dólares, y comprometido otros $\$ 5$ millones durante los siguientes diez años para mejoramientos comunitarios. La compañía financió la reparación de escuelas y la contratación de maestros para el sistema escolar de la comunidad. También construyó una clínica médica de 24 horas de servicio, adquirió y

\footnotetext{
${ }^{72}$ Informe Anual de Goldcorp Inc. (2006), “Goldcorp 2006 Annual Report”; en internet: http://www.goldcorp.com/_resources/financials/annuals/2006_Goldcorp_AR_web.pdf, p. 1 [“Goldcorp Annual Report (2006)"].

73 "World Factbook: Guatemala", en International Market Research Reports; en internet: Industry Canada http://strategis.ic.gc.ca/epic/site/imr-ri.nsf/en/gr-05098e.html.

${ }^{74}$ E-mail de Jeff Wilhoit, de Goldcorp, a Dawn Paley (1 de febrero de 2007); en internet: Business \& Human Rights Resource Centre http://www.businesshumanrights.org/Search/SearchResults?SearchableText=paley ["Wilhoit Email"]. "El presidente Berger ha señalado que Goldcorp es el mayor contribuyente que ha habido jamás en Guatemala."

${ }^{75}$ Anexo al Informe de la CAO (2005), “Annex to CAO Report (2005)”, nota 32, p.16. De un total de $\$ 69.9$ millones, $\$ 3.9$ millones corresponden a regalías pagadas al gobierno; San Miguel recibe adicionalmente $\$ 3.9$ millones en regalías, y Sipacapa obtendría $\$ 778,000$.

${ }^{76}$ Nota de prensa de Glamis: "Glamis Gold Comments on IFC Compliance Office Report on Marlin Project” (8 de septiembre de 2005).

${ }^{77}$ Anexo al Informe de la CAO (2005), nota 32, p. 15.
} 
equipó una ambulancia y un helicóptero de rescate, e instaló sistemas de cloración en los sistemas de abastecimiento de agua de ambos municipios ${ }^{78}$.

La realización de estas actividades dio a Glamis una imagen atractiva, y en febrero de 2005, antes de realizarse la consulta, el Banco Mundial se refería a la empresa como "un buen ciudadano corporativo", Desde entonces, muchas cosas se han descubierto.

El primer análisis claro de los problemas con el enfoque de Glamis apareció en un informe encargado por el propio Banco Mundial. Tras una reclamación que se le hiciera en marzo de 2005, antes de que se efectuase la consulta, el Banco encargó a la Oficina del Asesor en Cumplimiento/Ombudsman (CAO) que investigara la queja. Esta Oficina se encuentra bajo la supervisión directa del presidente del $\mathrm{BM}^{80}$. En este caso, la CAO preparó dos informes, ambos escritos después de la consulta -el primero en septiembre de 2005 y el segundo en mayo de 2006. Aunque redactados con lenguaje neutral, los informes ofrecen una relación metodológica de los fallos del gobierno guatemalteco y de Glamis. Resaltaremos aquí dos de los aspectos: el medioambiental y el de la consulta.

El aspecto medioambiental tiene que ver con el uso del proceso de lixiviación con cianuro ${ }^{81}$. Debido a la configuración montañosa de la zona, los embalses que contienen las aguas residuales no están alineados, y entonces Glamis supuestamente rebaja hasta niveles apropiados el contenido de cianuro

\footnotetext{
${ }^{78}$ Ibíd.; "Marlin Fact Sheet", nota 34, p. 2. Según Ladan Mehranvar, algunos miembros de la comunidad cuestionaron que tales proyectos se hubieran en realidad ejecutado.

${ }^{79}$ Carta de Rashad Kaldany, director del Departamento de Petróleo, Gas, Minería e Industrias Químicas de la CFI, a Shin Imai (22 de febrero de 2005).

80 La Oficina del Asesor en Cumplimiento/Ombudsman (CAO) constituye uno de los mecanismos más importantes de que dispone el Banco Mundial para asegurarse de que el beneficiario de un préstamo cumple con los estándares medioambientales y de derechos humanos. La CAO puede actuar en calidad de ombudsman y mediar en las disputas relacionadas con el cumplimiento de normas y acuerdos (véase Susan Park, "Assessing the Accountability of the World Bank Group"; en internet: http://www2.warwick.ac.uk/fac/soc/csgr/activitiesnews/workshops/forthcoming/wbbled/pa pers/park.pdf, p. 26. Otro mecanismo de supervisión es el Consejo de Inspección, que reporta ante los directores ejecutivos del Banco y tiene un papel investigativo y de asesoría (véase Clark, ibíd., p. 17). Para conocer el funcionamiento de un tercer mecanismo, las evaluaciones que realiza la Agencia Multilateral de Garantías de Inversiones (AMGI), véase David Szablowski, Transnational Law and Local Struggles: Mining, Communities and the World Bank (Oxford and Portland: Hart, 2007). Los dos últimos mecanismos mencionados no desempeñaron ningún papel en el caso de Glamis.

${ }^{81}$ Informe de la CAO (2005), nota 30, p. 15.
} 
en el agua, antes de enviarla a los embalses ${ }^{82}$. La posible contaminación de las aguas de uso público, debido al empleo del cianuro, constituye una seria preocupación medioambienta ${ }^{83}$.

La gente de Sipacapa estaba particularmente preocupada por este problema, tanto por tener que compartir el uso del agua con la mina como por su posible contaminación. El informe de la CAO observaba que la evaluación original de Glamis acerca de eventuales afectaciones medioambientales era incorrecta, porque había reportado que ninguna persona vivía corriente abajo a partir del dique de colas. El informe llegaba entonces a calificar de inexplicable cómo la CFI había determinado que era adecuada la evaluación sobre el impacto medioambiental y social que se requiere para aprobar el financiamiento ${ }^{84}$.

No obstante, la CAO concluyó que no existía riesgo significativo de contaminación del agua empleada por las comunidades cercanas a la mina, incluyendo a Sipacapa ${ }^{85}$. Igualmente determinó que, en razón del diseño avanzado de las instalaciones mineras, Sipacapa no experimentaría ninguna escasez de agua ${ }^{86}$. Desde la publicación de este informe se han emitido

82 "Resumen de la Evaluación del Impacto Medioambiental"; en internet: "Environmental Impact Assessment Summary", IFC http://www.ifc.org/ifcext/spiwebsite1.nsf/c9aba76ed1df1938852571c400727d66/060a86a9 $06546 \mathrm{c} 1 \mathrm{c} 852576 \mathrm{c} 10080 \mathrm{cc} 1 \mathrm{f}$ ?opendocument

${ }^{83}$ Una indicación de la naturaleza controversial del cianuro es el hecho de que su uso en la minería ha sido prohibido en el Estado de Montana (Estados Unidos) desde 1998: "I-137: Ban on Cyanide Mining"; en internet: Montana Environmental Information Center ("MEIC"): http://www.meic.org/mining/cyanide_mining/ban-on-cyanide-mining/i-137. Por otra parte, una mina de la empresa Cambior en Guyana permanece cerrada hasta que los planes medioambientales de la compañía puedan ajustarse a los requerimientos del gobierno francés: Cambior Inc., Press Release, "Update Camp Caiman Project" (11 de octubre de 2006); en internet: Cambior Inc. http://www.cambior.com/2/communiques/2006/06-10-11_EN_CampCaiman_Final.pdf. En particular, el gobierno muestra preocupación por el manejo y la contención del cianuro; véase la nota $155 \mathrm{y}$ el texto acompañante, que se refieren a un gran derrame de cianuro por Cambior en Guyana, que dio lugar a la presentación de una demanda ante la justicia canadiense. El empleo del cianuro en la minería aurífera no está prohibido en Canadá, pero su uso sí se regula con respecto al proceso de molido (como proceso reactivo): Fisheries Act: Metal Mining Effluent Regulations, 6 de junio de 2002, SOR/2002-222 (QL). Vease el Plan de Acción Ambiental de Glamis, donde se encuentra una lista de los riesgos y peligros en el Parte 1.2.1; en internet: http://www.ifc.org/ifcext/spiwebsite1.nsf/c9aba76ed1df1938852571c400727d66/060a86a9 06546c1c852576c10080cc1f/\$FILE/PLAN\%20DE\%20ACCI\%C3\%93N\%20AMBIENTA L.pdf

${ }_{85}^{84}$ Informe de la CAO (2005), nota 30, p. 20.

${ }^{85}$ Ibíd., p. i.

${ }^{86}$ Ibíd., p.ii. 
diversas opiniones con respecto a los impactos medioambientales de la mina Marlin. Un análisis técnico del hidrogeólogo Robert Moran, contratado por el grupo ecologista Madre Selva, afirma que el colega consultado por la CAO para la confección de su informe no visitó nunca la mina, y que había basado su dictamen en documentos que le facilitó Glamis. Asimismo, Moran encontró que las evaluaciones contenidas en el informe de la CAO eran muy simplistas y no tomaban en consideración muchos factores y contingencias a largo plazo. Por ejemplo, al realizar la prueba de drenaje de rocas ácidas, el hidrogeólogo empleado por la CAO solo lo hizo durante un período de veinte semanas, cuando -como indica Moran- muchos en la industria la realizan por un tiempo mucho mayor, de entre 40 semanas a un año, a fin de predecir apropiadamente la posible evolución de este proceso hidrogeológico ${ }^{87}$.

El segundo aspecto se relaciona con la consulta que se realizó entre la población del área. El Convenio 169 de la OIT establece claramente que los estados deben consultar a los pueblos indígenas "antes de emprender o autorizar cualquier programa de exploración o explotación" de los recursos del subsuelo $^{88}$. Sin embargo, en este caso no hubo tal consulta por parte del gobierno guatemalteco ${ }^{89}$. Individuos de la comunidad que fueron contratados para ofrecer información después de haberse otorgado la concesión, no tocaron el punto de los impactos medioambientales de las actividades mineras $^{90}$. La Evaluación de Impacto Ambiental (EIA) llevada a cabo por Glamis era insatisfactoria, en cuanto que "los temas de drenaje de roca ácida,

${ }^{87}$ Madre Selva y Robert Moran, "Respuesta al Informe Evaluativo de la CAO" (22 de septiembre de 2005); en internet: http:/www.cao-ombudsman.org/cases/documentlinks/documents/MadreSelvaResponseCAOAssessmentwithTechnicalReviewAnnexSpanis h.pdf

${ }^{88}$ Convenio sobre los Pueblos Indígenas y Tribales en los Países Independientes (No. 169), que entró en vigor el 5 de septiembre de 1991; en internet: http://white.oit.org.pe/ipec/documentos/169.pdf, artículo 15.2 [Convenio 169 de la OIT].

${ }^{89}$ Anexo al Informe de la CAO (2005), nota 32, p. 22: "En este período no hay registros de consulta y divulgación. La CAO no recibió prueba alguna de que se haya consultado o notificado a los municipios de San Miguel o Sipacapa ni a los terratenientes antes ni durante el otorgamiento del permiso de exploración."

${ }^{90}$ Informe de la CAO (2005), nota 30, p. 30: "Sin embargo, el personal del GRC [Grupo de Relaciones Comunitarias] expresó que en general escuchó continuas inquietudes sobre el impacto ambiental del proyecto, tanto en la municipalidad de Sipacapa como en la de San Miguel, y notó que no podían explicar los impactos del proyecto ni los planes de mitigación, como por ejemplo, por qué las exigencias de agua del proyecto no impactarían a los usuarios locales y cómo se mitigaría la contaminación potencial de los recursos de agua. Esto sugiere que el GRC requiere capacidad adicional y apoyo de personal técnico, para abordar adecuadamente las preocupaciones sobre la mina, que trae la comunidad". 
seguridad de diques y manejo del cianuro no estaban muy bien definidos"91. La propia evaluación era altamente técnica, y no se presentó como una consulta, sino como un fait accompli. La CAO sugiere que esta carencia de información pudo haber conducido a la firma de una declaración de apoyo a la mina, por parte de algunos líderes en San Miguel y Sipacapa, en la etapa temprana del proyecto. La CAO informa que este apoyo inicial se ha disipado, y que "los reclamantes creen que Sipacapa ha sido descuidada en el proceso de consultas y que el proyecto ha fallado en sus obligaciones de involucrarlos en el proceso de aprobación de licencias" $"$. Finalmente, en su informe de mayo de 2006 la CAO lanza una señal de alerta con relación a las exploraciones de Glamis en Sipacapa, al sugerir que “[...] la compañía declare en forma voluntaria una suspension temporaria de las actividades de exploración en Sipacapa", debido a "... los riesgos de proseguir las actividades de exploración en Sipacapa, en particular dado el clima actual de tensa calma..."

Aunque se celebraron muchas reuniones, la CAO observó que el pueblo de Sipacapa manifestaba insatisfacción con el proceso, y señaló la "[...] falta de claridad acerca de si los impactos potenciales del proyecto fueron transmitidos a la población local, y cómo, en comparación con discusiones más generales sobre [sus] beneficios" ${ }^{93}$.

En el contexto de las diferentes preocupaciones expresadas por la CAO, se obtiene un atisbo de que toda la actividad emprendida por Glamis no emana de una simple y noble buena voluntad. Glamis había enfrentado una fuerte oposición a la mina, y estas "consultas" pueden haber obedecido más a la auto-promoción que al cumplimiento de la obligación legal fijada por la Corte de Constitucionalidad de Guatemala, de "lograr acuerdos o alcanzar consensos" ". Vistas bajo esta luz, las campañas informativas conducidas por Glamis, que han llegado a "decenas de miles" de personas, pueden ser

\footnotetext{
91 Ibíd. "Las divulgaciones públicas sobre los impactos del proyecto y sus riesgos potenciales, preparadas por la compañía - incluso EIA - eran altamente técnicas y en ese momento no tenían suficiente información para permitir una opinión informada sobre los probables impactos adversos del proyecto. En particular, los temas de drenaje de roca ácida, seguridad de diques y manejo del cianuro no estaban muy bien definidos." Ibíd., p. 30: "Gran parte de la actividad de divulgación y consulta tuvo lugar después de completarse el EIA, y es razonable cuestionar el grado en el que tuvieron oportunidad de participar significativamente en el proceso de EIA."

${ }^{9}$ Ibíd., p. 28.

${ }^{93}$ Informe de la CAO (2005), nota 30, p. 31.

${ }^{94}$ Corte, nota 47, p. 27.
} 
consideradas un tanto como un amenazante uso del poder económico y político $^{95}$.

Quizá esta impresión pueda apreciarse mejor si se adopta la perspectiva de la población indígena. Entre 1962 y 1996 se produjeron 15 masacres en el Departamento de San Marcos ${ }^{96}$. La compañía minera llegó a Guatemala solo tres años después de que se hubieran firmado los acuerdos de paz. Es evidente que los habitantes de Sipacapa y San Miguel Ixtahuacán no percibieron claramente en los primeros momentos el potencial impacto de la mina. Cuando esta comenzó a hacerse realidad, lo hizo contra el trágico trasfondo de la historia reciente en el área. El sobrevuelo de aviones de reconocimiento y helicópteros habría revivido los malos recuerdos de la guerra, al igual que el despliegue de militares para cuidar la mina y el uso de fuerzas privadas de seguridad, que evidentemente incluían a antiguos miembros del ejército ${ }^{97}$. Estos temores se exacerbaron por la muerte a manos de los militares de Raúl Castro Bocel, el manifestante de Sololá, y el asesinato de Álvaro Benigno por la firma de seguridad privada al servicio de Glamis. Y para completar todo este escenario, estaban las amenazas de muerte contra el obispo Álvaro Razazzini y otros.

La CAO expresó sus críticas sobre la poca atención que prestaba Glamis a los temas de seguridad:

La ausencia de una clara política sobre derechos humanos, y sobre el manejo de las fuerzas de seguridad, constituye una falla, tanto por parte de la compañía como de la CFI, con respecto a una salvaguarda adecuada contra la posible violencia... La población local sigue gravemente preocupada por este asunto, pero hasta el momento la compañía no ha establecido una política para el manejo de las fuerzas de seguridad ${ }^{98}$.

\footnotetext{
95 E-mail de Wilhoit, nota 74: "Se ha consultado apropiada y documentadamente a las comunidades locales, y las campañas informativas continúan siendo una parte importante de nuestro esfuerzo por mantener las relaciones con la comunidad. En el curso de nuestras frecuentes visitas y de la celebración de foros de discusión, fácilmente decenas de miles de personas han sido consultadas, y se les han solicitado opiniones, sugerencias $y$ recomendaciones".

${ }^{96}$ Comisión de Esclarecimiento Histórico (CEH), cap. 2, vol. 3, párr. 730; en internet: http://shr.aaas.org/guatemala/ceh/mds/spanish/cap2/vol3/masacres.html.

${ }^{97}$ Informe de la CAO (2005), nota 30, p. 34. De acuerdo con el informe, la ley guatemalteca exige la presencia de militares por razones de seguridad con respecto a los explosivos.

${ }^{98}$ Ibíd., p. 35.
} 
Glamis dio algunos pasos para solucionar el asunto, incluyendo la adopción de los Principios Voluntarios de Seguridad y Derechos Humanos, establecidos por un acuerdo anglo-norteamericano ${ }^{99}$. No obstante, se afirma que continuaron la intimidación y los ataques contra los líderes comunitarios. El informe de un miembro de una ONG de derechos humanos describe así la situación en julio de 2006:

El 5 de julio, Mario Tema, líder comunitario sipacapense y antiguo alcalde municipal, iba en camino a Huehuetenango con su esposa cuando fueron seguidos por una camioneta verde, sin placas de matriculación. Varios miembros de la comunidad han informado a Tema sobre conversaciones que han escuchado, de individuos que proclaman su intención de deshacerse de él en la misma forma que se hizo con su padre, asesinado en 1987.

Se dan también esfuerzos concertados por criminalizar y deslegitimar a los líderes comunitarios que han estado en Sipacapa al frente de la lucha por la consulta, y que han mantenido una clara posición contra las actividades mineras en el municipio. Hay al menos tres falsas acusaciones, principalmente por amenazas y posesión de armas, contra los dirigentes Mario Perfecto Tema Bautista, Horacio Bamaca Mejía, Santos Arnulfo López, Sergio Carrillo Tojil y Eliseo Bamaca ${ }^{100}$.

Pero a pesar de todo, la oposición continúa creciendo. Esto se demuestra por los acontecimientos ocurridos en el municipio de San Miguel Ixtahuacán, donde se localiza el $85 \%$ de la mina. La mayor parte de la tierra de este municipio fue comprada por la mina, y en septiembre de 2005 la CAO informaba que no había reclamaciones por parte de los vendedores. En enero de 2007, decenas de manifestantes bloquearon las entradas a la mina durante

${ }^{99}$ Banco Mundial/CFI, "Respuesta al Informe de la CAO (2005) (14 de octubre de 2005); en internet: $\mathrm{CAO}$ http://www.cao-ombudsman.org/html-english/documents/MarlinResponsetofinalreport.pdf, p. 4. El texto de los Principios Voluntarios de Seguridad y Derechos Humanos puede encontrarse http://www.voluntaryprinciples.org/files/principios_voluntarios_espanol.pdf

${ }_{100}$ Sandra Cuffe, "San Miguel Ixtahuacán Announces Community Consultations \& Sipacapa Community Leaders Face Ongoing Repression" (20 de julio de 2005); en internet: GlobalExchange, http://www.globalexchange.org/countries/americas/guatemala/3354.html. 
una semana, en protesta por estas transacciones ${ }^{101}$. Después, en marzo de 2007, un grupo denominado Frente Comunal de Resistencia contra la Explotación Minera, localizado en San Miguel Ixtahuacán, emitió una declaración en la que manifestaba que los miembros de la comunidad habían sido presionados e intimidados para que vendieran sus tierras. El grupo denunciaba el agotamiento de las fuentes de abasto de agua, y la muerte de animales a causa de los diques de colas $^{102}$. El 2 de mayo de 2007, otra organización de San Miguel, la Asociación para el Desarrollo Integral Sanmiguelense (ADISMI), envió una carta a los accionistas de Goldcorp en la que revelaba que dos de sus miembros habían sido hechos prisioneros en medio de la noche por el ejército guatemalteco, y que había órdenes de arresto contra otros catorce. Decía la carta: "Todo esto porque estos miembros de la comunidad denuncian que fueron engañados cuando empleados de su compañía llegaron a despojarlos de sus tierras mediante la fuerza y la coerción" $" 103$.

Puede ser que los arrestos hayan respondido a la presión de Goldcorp para que se ejerciera una acción directa contra quienes se oponían a la mina. En febrero de 2007, un portavoz de la compañía escribió que Goldcorp había pedido "que las autoridades investigaran si los conflictos sociales y medioambientales se fabricaban con el propósito de fomentar las luchas políticas en el país"104.

De manera que desde la perspectiva de los indígenas ellos se enfrentan a una gran compañía minera, con recursos aparentemente ilimitados como para contratar guardias, acceder al sistema legal y obtener el apoyo del presidente de la república. La empresa tiene fondos para invertir en reuniones comunitarias en las que obtiene información, y decide qué hacer con ella.

101 "Guatemalan gold mine operations slowed by protests", Reuters News (17 de enero de 2007).

${ }^{102}$ Comunicado de prensa y declaración de las Comunidades en Resistencia en San Miguel Ixtahuacán, San Marcos, Guatemala, a la Opinión Pública Nacional e Internacional (7 de marzo de 2007); en internet: http://portal.rds.org.hn/ listas/medio-ambiente/msg01394.html.

${ }^{103}$ ADISMI, "Carta de las Comunidades en Resistencia, a la Goldcorp" (2 de mayo de 2007); en internet: Fredericton Peace Coalition, http://frederictonpeace.org/? $p=562$; e-mail de Wilhoit, nota 74. Goldcorp argumenta: "Estos bloqueos de carreteras fueron orquestados por un pequeño grupo de individuos que expresaban su insatisfacción con los acuerdos de ventas de tierra a los que habían llegado con Goldcorp. En suma, estas personas pedían más dinero, a pesar de haber recibido un buen pago, en exceso del valor de mercado. Con relación a los bloqueos propiamente dichos, estamos decepcionados porque en vez de un diálogo constructivo, los organizadores de los bloqueos prefieran emplear el hostigamiento, las amenazas y la intimidación para plantear sus demandas."

${ }^{104}$ E-mail de Wilhoit, nota 74. 
La población indígena de Sipacapa y San Miguel de Ixtahuacán, por su parte, cuenta con muy poco. Se la abruma con información, pero no puede expresar realmente su criterio sobre el desarrollo de la mina. No puede confiar en los militares ni en el gobierno. Tiene poco en términos de recursos financieros, poder político, acceso a la justicia o incluso protección personal. Uno de los pocos caminos que le queda es la protesta pública y el bloqueo de carreteras.

\section{RESTRICCIONES DENTRO DE GUATEMALA}

Para Glamis, el hecho de que se estuviera violando el derecho indígena quizá no importara. Creía que solo era válida la ley guatemalteca. Y ahora Goldcorp descansa en el hecho de que cumple con las leyes de Guatemala ${ }^{105}$.

En los días anteriores a la consulta, el Ministerio de Energía y Minas llevó el caso ante la Corte de Constitucionalidad, para impedir que el evento tuviera lugar. La Corte pronunció su decisión en el caso Sipacapa el 8 de mayo de 2007, casi dos años después de que el caso se iniciara. Los argumentos avanzados por el Ministerio de Energía y Minas planteaban tanto la ilegalidad del proceso de consulta como del intento de hacer vinculante la decisión para la mina. Decía el ministerio que la comunidad indígena solo podía ejercer la autoridad que le garantizara la legislación guatemalteca, y aducía también que los recursos del subsuelo pertenecían al Estado guatemalteco, y que una municipalidad no podía realizar una consulta sobre una materia que no estaba bajo su jurisdicción ${ }^{106}$.

La Corte de Constitucionalidad reprendió duramente tanto al gobierno como a la mina con respecto al proceso de consulta, al decidir que "las consultas populares constituyen mecanismos importantes de expresión popular ${ }^{107}$. La decisión puntualizaba que la resolución municipal que establecía la consulta pedía una amplia divulgación del evento, y que no hubiera ninguna dificultad para obtener las copias certificadas de la resolución al inicio del proceso ${ }^{108}$.

105 E-mail de Wilhoit, Ibíd: "Dos decisiones judiciales de aquel momento establecieron que las consultas eran inconstitucionales. Estas decisiones están todavía en vigor. El criterio de Goldcorp es que nos atendremos al orden legal que se defina por los tribunales y los organismos gubernamentales de Guatemala."

${ }^{106}$ Corte, nota 47 , pp. $14-15$.

${ }^{107}$ Ibíd., p. 26.

${ }^{108}$ Ibíd., p. 25: [El] Acta cero nueve-dos mil cinco (09-2005) establece que el Concejo Municipal y el Concejo Municipal de Desarrollo Urbano y Rural publicarán, por todos los medios a su alcance, el objeto del procedimiento consultivo, por lo que no se aprecia que los acuerdos restrinjan la posibilidad de conocer la convocatoria. Además, la accionante expone, en el escrito inicial, que pudo obtener copias certificadas de las actas referidas a la convocatoria. 
La Corte urgía entonces al gobierno a que hiciera efectivo el requerimiento de consulta a los pueblos indígenas antes de cualquier exploración mineral, establecido en el Convenio 169 de la OIT, mediante la reglamentación de los procesos de consulta con vista al futuro ${ }^{109}$. Claramente, la Corte no aceptó las aseveraciones de Glamis de que no había tenido lugar una consulta adecuada, o de que el proceso organizado en Sipacapa fuera innecesario y "corrupto".

La Corte va más lejos en su crítica, al señalar que el objetivo de la consultación no es simplemente revelar los sentimientos de la comunidad, sino "lograr acuerdos o alcanzar consensos acerca de las medidas propuestas"110. El tribunal constitucional declara enfáticamente que la actividad minera debe "ofrecer justa compensación a las regiones donde [esta actividad] se realiza, por medio de medidas económicas y sociales de desarrollo comunitario"111. No obstante, la Corte encontró que la consulta no era vinculante dentro de la ley guatemalteca, porque la autoridad minera corresponde al Ministerio de Energía y Minas ${ }^{112}$.

La justicia guatemalteca no ha sido capaz de erigirse en contrapartida efectiva del ejercicio del poder estatal.

En el caso Sipacapa, la Corte de Constitucionalidad hizo algunos señalamientos muy justos sobre la conducta de Glamis y del gobierno de Guatemala. Aun así, no se decidió a detener la exploración. En verdad, podía haber adoptado el enfoque de la Corte Suprema de Canadá y haber requerido

${ }^{109}$ Convenio 169 de la OIT, nota 88, artículo 15: “(1) Los derechos de los pueblos interesados en los recursos naturales existentes en sus tierras deberán protegerse especialmente. Estos derechos comprenden el derecho de esos pueblos a participar en la utilización, administración y conservación de dichos recursos. (2) En caso de que pertenezca al Estado la propiedad de los minerales o de los recursos del subsuelo, o tenga derechos sobre otros recursos existentes en las tierras, los gobiernos deberán establecer o mantener procedimientos con miras a consultar a los pueblos interesados, a fin de determinar si los intereses de esos pueblos serían perjudicados, y en qué medida, antes de emprender o autorizar cualquier programa de prospección o explotación de los recursos existentes en sus tierras. Los pueblos interesados deberán participar siempre que sea posible en los beneficios que reporten tales actividades, y percibir una indemnización equitativa por cualquier daño que puedan sufrir como resultado de esas actividades".

${ }^{110}$ Corte, nota 47, p. 27.

${ }^{111}$ Ibíd.

112 Ibíd., p. 21: “[La] Ley del Organismo Ejecutivo designó al Ministerio de Energía y Minas, en su articulo 34, literal c), como responsable de las políticas de exploración, explotación y comercialización de minerales." 
que la consulta tuviera lugar antes de que la compañía interpusiera un nuevo recurso $^{113}$.

El Estado guatemalteco convive aún con el poder de los militares y sus dictadores. Existen poderosas fuerzas democráticas en el país, y personas en el gobierno, el ejército y las diferentes Iglesias que desean moverse adelante, pero los exdictadores no han tenido que abandonar el país o responder a ningún emplazamiento judicial. De hecho, continúan presentándose como candidatos en las elecciones. Por ejemplo, Ríos Montt, el dictador en ejercicio a principios de los años 1980, durante el peor período de violencia en Guatemala, fue electo presidente del Congreso guatemalteco en el año $2000^{114}$. Incluso tras un fallo de la Corte de Constitucionalidad, Montt fue capaz de presentarse como candidato en las elecciones presidenciales de $2003^{115}$.

Ese mismo año, el coronel que ordenó la muerte en 1990 de la antropóloga forense Myrna Mack fue puesto en libertad por un tribunal inferior, solo un año después de habérsele sentenciado. Y pese a un nuevo fallo de la Corte Suprema de Justicia, que confirmó su condena a causa de la presión nacional e internacional, el coronel ha eludido su detención ${ }^{116}$.

Las amenazas de muerte y los asesinatos de activistas de derechos humanos son hechos comunes en Guatemala -incluso en 2007. El sitio web de Amnistía Internacional anuncia como Casos de Acción Urgente al menos dos por mes con relación a Guatemala. Uno de estos Casos de Acción Urgente se refiere al grupo que continúa llevando adelante el trabajo de la asesinada antropóloga Myrna Mack, para lograr la identificación de las víctimas de las masacres ${ }^{117}$. La activista indígena Rigoberta Menchú, Premio Nobel de la Paz, vive también bajo amenaza de muerte. Menchú aspira a la presidencia de la república en las elecciones de 2007, al frente del partido Encuentro por Guatemala (EG). En agosto de 2007, desconocidos tirotearon la residencia de la candidata Olga Marina Lucas López, de este partido, y sus dos hijas (de 15 y 20 años de edad) resultaron heridas. Pocos días antes, se intentó contra la

\footnotetext{
${ }^{113}$ En Canadá existe un abundante cuerpo legal que define los parámetros de las consultas. El caso más relevante es Haida Nation v. British Columbia, [2004] 3 Supreme Court Reporter 511.

114 Susanne Jonas, "Democratization through Peace: The Difficult Case of Guatemala" (2000) 42:4 J., Interamerican Studies and World Affairs, edición especial: Globalization and Democratization in Guatemala, p.31.

115 "The Americas: General riot: Guatemala's Election Row", The Economist 368:8335 (2 de agosto de 2003), p. 53.

116 "International Court Condemns Guatemala over Murder", Reuters News (19 de diciembre de 2003).

117 Amnistía Internacional, "Guatemala"; en internet: Amnesty International, Urgent Actions http://web.amnesty.org/library/eng-gtm/index
} 
vida de César Montes, miembro del ejecutivo del EG. Todos estos actos eran la continuación de una cadena de anteriores asesinatos. En abril de 2006 fue muerto a balazos Esteban Tebalán, un coordinador del partido, y en octubre del mismo año corría igual suerte Eduardo Maaz, tío de un funcionario regional de esta organización política. En mayo de 2007 ocurrió lo mismo con Liverato Granados, un candidato a alcalde ${ }^{118}$.

Evidentemente, el Estado presenta obstáculos internos que le impiden dar protección a quienes defienden los derechos humanos de los indígenas. También es vulnerable ante las fuerzas económicas; tiene pocas entradas, y sus recursos naturales constituyen una importante fuente de ingresos. En consecuencia, se experimenta una gran incentivación para tratar el problema de la pobreza mediante la explotación de los recursos del subsuelo. Hay poco incentivo económico en la imposición de barreras a la minería, y la Corte de Constitucionalidad encontró que el Estado no posee mecanismos para cumplir con los requerimientos de consulta establecidos en el Convenio 169 de la $\mathrm{OIT}^{119}$.

Relacionada con la vulnerabilidad económica del Estado está la falta de capacidad del gobierno para supervisar la actividad minera. La CAO halló, por ejemplo, que el gobierno guatemalteco no era capaz de obligar a Glamis a cumplir con sus obligaciones medioambientales, y otras, en el proceso de operación de la mina ${ }^{120}$.

Puede verse que el Estado no ejerce un contrapeso efectivo frente a una gran corporación, en parte porque para el propio Estado constituye un desafío proteger los derechos humanos, y en parte porque el país es vulnerable a la necesidad económica.

\section{RESTRICCIONES INTERNACIONALES A LOS ACTORES NO INDÍGENAS}

Hay una variedad de medios posibles para ejercer presión sobre los estados con respecto a los derechos indígenas, incluyendo los mecanismos que imponen los instrumentos de Naciones Unidas y las disposiciones de la

\footnotetext{
${ }^{118}$ Julio Lara, Lorena Seijo, Jessica Osorio, "Se solidarizan con EG: Dos dirigentes del partido han sido atacados en menos de 48 horas" (9 de agosto de 2007); en internet: Prensa Libre http://www.prensalibre.com/pl/2007/agosto/09/179303.html

${ }^{119}$ Corte, nota 47, p. 27.

${ }^{120}$ Informe de la CAO (2005), nota 30, p. iii: "La CAO no encontró evidencias de la capacidad de la compañía, o del gobierno, para supervisar y controlar el proyecto.”
} 
Comisión Interamericana de Derechos Humanos ${ }^{121}$. Aquí nos centraremos en los instrumentos más relevantes con respecto al caso de Sipacapa: el Convenio sobre los Pueblos Indígenas y Tribales en los Países Independientes (Convenio 169 de la Organización Internacional del Trabajo), y las directrices del Banco Mundial.

El Convenio 169 exige a los gobiernos que consulten a los pueblos indígenas cuando alguna decisión legislativa afecte directamente a sus intereses $^{122}$. Bajo el convenio, los estados deben asegurar que los pueblos indígenas tengan libertad para participar en los órganos decisorios mediante representantes apropiados, y que estos esfuerzos de consultación se conduzcan de buena $\mathrm{fe}^{123}$. El objetivo de las consultas es llegar a un acuerdo u obtener el consentimiento de la comunidad indígena en relación con las acciones propuestas $^{124}$. Con respecto a la minería, se requiere de los estados que consulten a las comunidades antes de que se inicien las actividades de exploración o explotación ${ }^{125}$. Asimismo, los estados deben compartir con la comunidad indígena los beneficios de estas actividades mineras ${ }^{126}$.

Existen diferentes puntos de vista sobre cómo debe implementarse el convenio. En 2005 se discutió este tema en un taller internacional de la ONU acerca del concepto del libre y previo consentimiento informado. De acuerdo con el informe del taller, la consulta comprende una oportuna reunión con los pueblos indígenas, que permita a estos ejercer su influencia sobre el proyecto o sobre la decisión de proceder con la $\operatorname{propuesta~}^{127}$. El informe estipula que el

${ }^{121}$ Para un análisis general, véase Anaya, nota 66, y Szablowski, nota 80. Entre las normas internacionales que potencialmente pueden aplicarse están el Pacto Mundial de Naciones Unidas (2000), http://www.unglobalcompact.org/Languages/spanish/index.html; las Normas sobre las Responsabilidades de las Corporaciones Transnacionales y otras Empresas con Respecto a los Derechos Humanos, UN Doc. E/CN.4/Sub.2/2003/12/Rev.2 (2003), http://www1.umn.edu/humanrts/links/norms-Aug2003.html); las Directrices para las Empresas Multinacionales, de la Organización para la Cooperación y el Desarrollo Económico (OCDE) (2000), http://www.oecd.org/dataoecd/56/36/1922428.pdf, y los Principios de la CERES [siglas, por su nombre en inglés, de la Coalición por Economías Ambientalmente Responsables] http://www.surfrider.org.ar/index.php/?page_id=596.

${ }^{122}$ Convenio 169 de la OIT, nota 88, artículo 6.

${ }^{123}$ Ibíd.

${ }^{124}$ Ibíd.

125 Ibíd., artículo 15.

${ }^{126}$ Ibíd.

${ }^{127}$ Taller Internacional sobre el Consentimiento Libre, Previo e Informado y los Pueblos Indígenas, "Contribución de la OIT" (Nueva York, 17-19 de enero de 2005); en internet: http://www.un.org/esa/socdev/unpfii/documents/workshop_FPIC ILO.doc, p. 2, [“UN Prior Consent Workshop (2005)']. 
Estado debe reunirse con los representantes de la comunidad indígena, y que esta reunión debe ser más que una simple sesión informativa sobre la acción propuesta $^{128}$. El documento identifica dos principios fundamentales del Convenio 169. El primero promueve el derecho de las comunidades indígenas a determinar sus propias prioridades en relación con su futuro ${ }^{129}$. El segundo establece que los pueblos indígenas deben ser capaces de realizar cambios en los planes propuestos, mediante su participación activa en el proceso de toma de decisiones ${ }^{130}$. Estos principios obligan al Estado a justificar sus decisiones en temas que afecten a, o estén en conflicto con los deseos de los pueblos indígenas ${ }^{131}$. Pese a señalar estos principios, el informe no enfatiza que el consentimiento cabal de una comunidad indígena es un requerimiento necesario del convenio ${ }^{132}$.

La Comisión de Expertos en Aplicación de Convenios y Recomendaciones, de la OIT, analizó en su 77ma. Sesión (2006) el cumplimiento por parte de Guatemala del Convenio 169 en el caso de la mina de Glamis. La comisión observó que Guatemala había manifestado que estaba en proceso de desarrollar una legislación y un mecanismo para realizar la consulta. No obstante, expresó sus reservas acerca de la continuada actividad de exploración y explotación desarrollada por la compañía minera, y se preguntó si sería posible "realizar los estudios previstos en el artículo 7 del convenio, en cooperación con los pueblos concernidos, antes de que los potenciales efectos dañinos de estas actividades se hicieran irreversibles". La comisión pidió también una investigación sobre el asesinato ocurrido durante el bloqueo en Sololá ${ }^{133}$.

La OIT no está capacitada para hacer cumplir directamente las recomendaciones de la comisión de expertos, y debe descansar en la buena voluntad de los gobiernos. Este problema es común a otros instrumentos internacionales. En el caso de Guatemala, esta ratificó el Convenio 169 y lo incorporó a su legislación doméstica, pero no ha reglamentado los requerimientos de consultación. En el caso Sipacapa, la Corte de

\footnotetext{
${ }^{128}$ Ibíd.; Anaya, nota 66, p. 154.

${ }^{129}$ Taller, nota 127 , p. 3.

${ }^{130}$ Ibíd.

${ }^{131}$ Anaya, nota 66, p. 155.

132 Taller, nota 127 , p. 3.

${ }^{133}$ OIT, Comisión de Expertos en la Aplicación de Convenios y Recomendaciones, 77ma.

Sesión (2006), párr. 7; en internet:

http://webfusion.ilo.org/public/db/standards/normes/appl/appl-

displayAllComments.cfm?hdroff $=1 \&$ ctry $=0270 \&$ conv $=$ C $169 \&$ Lang $=$ sp
} 
Constitucionalidad exhortó al Estado a implementar la legislación pertinente, pero no llegó a aplicar directamente las disposiciones del Convenio ${ }^{134}$.

Las políticas operativas del Banco Mundial constituyen otra posible limitación. El Banco tiene la ventaja de poder dirigirse directamente a la corporación prestataria, y sus directrices son similares a los principios del Convenio 169. Estas directrices exigen de los prestatarios realizar "una consulta libre, previa e informada" con las comunidades indígenas que se verán afectadas por sus actividades ${ }^{135}$, y estipulan que esta consulta debe obtener un "amplio apoyo comunitario" antes de que el Banco decida financiar un proyecto ${ }^{136}$. Las consultas deben ser culturalmente apropiadas y respetar las instituciones y costumbres de cada comunidad ${ }^{137}$.

El Banco Mundial cuenta con el uso de sus fondos como influencia para lograr el cumplimiento. El informe de la $\mathrm{CAO}$, según se vio más arriba en relación con la disputa de Sipacapa, fue uno de los mecanismos empleados para determinar si Glamis estaba cumpliendo con las condiciones del préstamo. En noviembre de 2006 Goldcorp completó su adquisición de Glamis, y es ahora el nuevo propietario y operador de la mina Marlin. Casi de inmediato Goldcorp reintegró el préstamo por $\$ 45$ millones de dólares norteamericanos que le había hecho el Banco, y con ello se libró de cualquier compromiso con respecto a las directrices de la institución ${ }^{138}$.

\section{IX. ¿CUÁL ES LA RESPONSABILIDAD DEL GOBIERNO DE CANADÁ?}

La embajada de Canadá ha estado muy activa en la promoción de las explotaciones mineras de este país en Guatemala. El 4 de noviembre de 2004, solo dos días antes de una reunión comunitaria en San Marcos que trataría el tema de la mina, el embajador canadiense en aquel entonces, James Lambert, publicó en un diario guatemalteco un artículo de opinión que alababa a la industria minera de su nación por estar "a la vanguardia de la tecnología

\footnotetext{
${ }^{134}$ Corte, nota. 47, p. 27.

135 Banco Mundial, "Política Operacional sobre los Pueblos Indígenas 4.10”, (julio de 2005); en internet: Banco Mundial, http://siteresources.worldbank.org/OPSMANUAL/Resources/2103841170795590012/OP4.10.July1.2005.Spanish.pdf, párrs. 1, 6.

136 Ibíd.

${ }^{137}$ Ibíd, párrs. 1, 6, 10.

${ }^{138}$ Informe Anual de Goldcorp (2006), nota 72, p. 68. El préstamo se reintegró el 29 de diciembre de 2006.
} 
avanzada, la protección del medioambiente y la responsabilidad social"139. Lambert se explayaba en las similitudes entre Guatemala y Canadá, y decía que 1,200 comunidades indígenas canadienses se beneficiaban de la exploración minera ${ }^{140}$. Esto formaba parte de una campaña de la embajada para "obtener el apoyo público", que incluyó la invitación a un líder y periodista comunitario guatemalteco para viajar a la Columbia Británica por cinco días, con el fin de que conociera una instalación minera en una comunidad originaria. ${ }^{141} \mathrm{La}$ embajada también coordinó la asistencia del jefe indígena canadiense Phillip Asp a un foro sobre minería en Ciudad de Guatemala. Resulta irónico que la postura pro-minería del señor Asp no fuese apoyada por los líderes ancianos de su propia comunidad indígena, algunos de los cuales ocuparon la oficina del grupo, en protesta ${ }^{142}$.

En la zona de El Estor, el antiguo sitio minero de la corporación INCO, que se asociaba con los asesinatos de Exmibal en 1970, había sido ocupado por una nueva compañía minera canadiense, la Skye Resources. En enero de 2007 esta compañía logró que el ejército desalojara a cientos de pobladores indígenas de las tierras en disputa. En lugar de adoptar una posición neutral en el conflicto, el embajador de Canadá en ese momento, Kenneth Cook, arremetió contra los periodistas de su país presentes en el lugar, que filmaron los desalojos, acusándolos de haber utilizado a un actor e imágenes de otros sucesos con el fin de fabricar la historia. Se afirma que el embajador incluso habló con representantes de la Iglesia Católica en la región para desacreditar a estos periodistas. Un reportaje radial sobre los hechos se transmitió en el espacio de la CBC "As It Happens", con una entrevista al realizador de videos Steven Schnoor, quien dijo haber ofrecido entregar los negativos de las fotos.

139 James Lambert, "Colaboración Minería en Canadá”; en internet: Prensa Libre, http://www.schnoorversuscanada.ca/docs/prensa-libre-james-lambert.pdf. "Hoy en día, las empresas canadienses están a la vanguardia en alta tecnología, protección del medio ambiente y responsabilidad social. Es por eso que en la actualidad son ellas las que están al frente de muchas de las operaciones mineras más exitosas del mundo."

${ }^{140}$ Sería interesante saber de dónde sacó el embajador esta cifra, ya que no hay tantas reservas indígenas en Canadá. Incluso contando las comunidades inuit, se haría muy difícil alcanzar ese número. Y, ciertamente, no todas las comunidades se benefician de la explotación de los recursos naturales. Muchas, en verdad, se oponen a ello, y algunas han realizado bloqueos para impedirlo.

${ }^{141}$ Celeste Mackenzie, "Canadian mine in eye of storm", Toronto Star (27 de marzo de 2005), p. A14.

${ }^{142}$ Monte Paulsen, "Tahltan Resistence to Mining, Drilling Grows" (7 de marzo de 2005); en internet: The Tyee http://thetyee.ca/News/2005/03/07/TahltanResistanceGrows/. Al momento de escribirse este reportaje, los ancianos habían ocupado la oficina del grupo por ocho semanas. 
$\mathrm{Ni}$ el embajador Cook ni funcionarios del Departamento de Asuntos Extranjeros accedieron a ser entrevistados. Schnoor demandó al embajador por calumnia ante una corte en Ontario, y el juez decidió a su favor, señalando que el embajador había sido "negligente" y que "debía haberse informado mejor". A Schnoor se le concedió una indemnización de unos $\$ 10,000$ por daños y costas.

Nos preguntamos si resulta apropiado este tipo de apoyo a la industria minera por parte de la embajada canadiense. Dado el enorme desequilibrio de poder y la ausencia de mecanismos de supervisión y control dentro de Guatemala, ¿debería Canadá estar colocando su peso en un solo platillo de la balanza? En junio de 2005, la Comisión Permanente de Asuntos Extranjeros y Comercio Internacional del Parlamento canadiense emitió un informe titulado "La minería en los países en desarrollo y la responsabilidad social corporativa", que pedía al gobierno desempeñar un papel supervisor más responsable para asegurar que las compañías mineras se adhieran a los estándares internacionalmente reconocidos de derechos humanos, particularmente en relación con los pueblos indígenas.

La Comisión Permanente celebró una serie de audiencias para escuchar testimonios sobre las actividades de la industria extractiva canadiense en Colombia, Sudán, la República Democrática del Congo y Filipinas. La comisión observó que las compañías canadienses estaban establecidas en países "donde las regulaciones que gobiernan al sector minero y su impacto en el bienestar económico y social de sus empleados, y de los residentes locales, así como sobre el medioambiente, son débiles, no existen, o no se cumplen". Los parlamentarios expresaron su preocupación de que "Canadá no tiene aún leyes para asegurar que las actividades de las compañías mineras canadienses en los países en desarrollo estén en conformidad con los estándares de derechos humanos, incluyendo los derechos de los trabajadores y de los pueblos indígenas". La Comisión recomendó el establecimiento de "claras normas legales en Canadá para asegurar que a las compañías y los residentes canadienses se les haga responsables cuando existan pruebas de violaciones medioambientales y/o de derechos humanos relacionadas con la actividad de las compañías mineras canadienses" ${ }^{\prime 143}$.

143 "Respuesta del Gobierno al Decimocuarto Informe de la Comisión Permanente de Asuntos Extranjeros y Comercio Internacional: La minería en los países en desarrollo y la responsabilidad social corporativa"; en internet (en inglés): http://cmte.parl.gc.ca/Content/HOC/

committee/381/faae/govresponse/rp2030362/faae_rpt14_gvtrsp-e.htm> [“SCFAIT CSR Report']. 
El gobierno no respondió con la puesta en vigor esas normas legales, sino con la convocatoria a un proceso llamado Conferencias Nacionales en torno a la Responsabilidad Social Corporativa [RSC] y la Industria Extractiva Canadiense en los Países en Desarrollo ${ }^{144}$. Un Comité Asesor integrado por representantes de la sociedad civil, inversores y ejecutivos de la industria minera se reunió entre junio y noviembre de 2006 en Vancouver, Calgary, Toronto y Montreal. Tomando como base el informe de la Comisión Permanente del Parlamento, se seleccionaron cinco temas para guiar el proceso de las Conferencias: normas y prácticas de la RSC; incentivos para su implementación; asistencia a las compañías; supervisión de la RSC y establecimiento de mecanismos para la solución de diferendos; fortalecimiento de la capacidad de gobernanza. El informe del Comité Asesor, que se publicó el 29 de marzo de 2007, hacía recomendaciones sobre el incremento de la supervisión a las compañías extractivas canadienses en el exterior ${ }^{145}$. Sugería también la creación de la oficina de un ombudsman independiente, que brinde servicios de asesoramiento y búsqueda de información sobre reclamaciones acerca del funcionamiento de las compañías extractivas canadienses en los países en desarrollo. El informe, de igual modo, urge al gobierno a crear un comité de inspección que sea independiente del gobierno y los partidos. El papel de este comité es asegurar el cumplimiento de un grupo de normas canadienses sobre la responsabilidad social corporativa, basándose en las conclusiones del ombudsman con respecto a las reclamaciones, y recomendar las respuestas más apropiadas en tales $\operatorname{casos}^{146}$. El informe aconseja que el gobierno federal sea más agresivo en el uso de los incentivos financieros, tales como las inversiones realizadas por la Corporación para el Desarrollo de las Exportaciones (CDE) y el Plan de Pensiones de Canadá ${ }^{147}$. En el caso de

\footnotetext{
${ }^{144}$ Ibíd.

145 Conferencias Nacionales en torno a la Responsabilidad Social Corporativa [RSC] y la Industria Extractiva Canadiense en los Países en Desarrollo, "Informe del Comité Asesor" (29 de marzo de 2007); en internet: Foreign Affairs and International Trade Canada, http://geo.international.gc.ca/cip-

pic/library/Advisory\%20Group\%20Report\%20\%20March\%202007.pdf,[“CSR

Roundtables"].

${ }^{146}$ Ibíd.

147 Ibíd., pp. xi-xiii, 39. El incumplimiento por parte de las compañías de estas normas de responsabilidad social corporativa debería llevar a la suspensión de su financiamiento por la CDE. También el Plan de Pensiones debe realizar un trabajo de supervisión, e informar acerca de la implementación de su Política sobre Inversión Responsable.
} 
Goldcorp, esto pondría en riesgo la inversión que hizo en ella el Plan de Pensiones, por un valor de $\$ 181$ millones de dólares canadienses ${ }^{148}$.

El informe concibe para Canadá un papel que responda a la preocupación por los derechos humanos, especialmente con respecto a los pueblos indígenas. Por ejemplo, señala lo siguiente:

La determinación por parte del gobierno de Canadá de que una compañía ha incumplido gravemente con las normas canadienses sobre la RSC, debe conducir al retiro de su apoyo ulterior. El gobierno de Canadá debe desarrollar políticas y directrices para evaluar estos incumplimientos. Entre otras cosas, al decidir si se ha producido o no ese grave incumplimiento, el gobierno debe tener en cuenta un dictamen del Comité de Inspección de que la compañía no cumple con las normas canadienses de la RSC ni con cualesquiera otras recomendaciones relevantes que les estén asociadas ${ }^{149}$.

A fin de cumplir con este papel supervisor, el gobierno tendría que contar con informes evaluadores de sus embajadas, y esto implica que los embajadores deben adoptar una posición más neutral que la mantenida hasta hoy día al evaluar la conducta de las compañías extractivas canadienses en el exterior.

No hubo consenso en el Comité Asesor sobre la necesidad de la legislación que recomendaba la Comisión Permanente de Asuntos Extranjeros y Comercio Internacional. Aunque las $\mathrm{ONG}$ canadienses pedían que se implementara esta legislación, los representantes de la industria no estaban a favor de ninguna ley similar a la norteamericana Ley de Reclamaciones contra Infracciones cometidas en el Extranjero, que permite que las compañías estadunidenses sean demandadas ante tribunales de Estados Unidos por nacionales de los países donde están establecidas, por infracciones que hayan cometido en esos países ${ }^{150}$. En correspondencia con esta ley, actualmente está siendo enjuiciada en Estados Unidos la compañía canadiense Talisman Energy,

148 Plan de Pensiones de Canadá: CPP Investment Board, "Canadian Equity Holdings: As of March 31, 2007'; en internet:

http://www.cppib.ca/files/PDF/CDN_Equity_Holdings_March31_2007___ENG.pdf

${ }_{149}$ Conferencias Nacionales en torno a la RSC, nota $14 \overline{5}$, pp. xiii, 48.

${ }^{150}$ Craig Scott y Robert Wai, "Transnational Governance of Corporate Conduct through the Migration of Human Rights Norms: The Potential Contribution of Transnational 'Private' Litigation", en C. Joerges, P. Sand y G. Teubner, eds., Transnational Governance and Constitutionalism (Oxford: Hart, 2004), pp. 287-294, 315; Madelaine Drohan, Making a Killing: How and Why Corporations Use Armed Force to Do Business (Toronto: Random House Canada, 2003), p. 327. 
por su supuesta complicidad en las masacres perpetradas en Sudán ${ }^{151}$. Un representante de esta empresa fue miembro del Comité Asesor.

El informe del Comité Asesor simplemente brinda recomendaciones para el futuro; no ofrece medios inmediatos para supervisar y controlar el poder económico y político del que están investidas las corporaciones extractivas canadienses en países como Guatemala.

Significativamente, no obstante, el informe analiza la posibilidad de emplear los tribunales canadienses para propiciar alguna vía al enjuiciamiento penal y a las demandas civiles en caso de infracción. Por ejemplo, con respecto al enjuiciamiento penal el Comité Asesor piensa que Canadá tiene un "brazo razonablemente largo". ${ }^{152} \mathrm{Y}$ con respecto a los juicios civiles, el gobierno federal había señalado con anterioridad, en su respuesta al informe de la Comisión Permanente de Asuntos Extranjeros y Comercio Internacional, lo siguiente:

Recursos legales para tratar las violaciones de los derechos medioambientales o humanos se encuentran también en la legislación civil, no solo en la penal. En la medida en que crímenes o infracciones como el daño al medioambiente o las lesiones personales, cometidos fuera de Canadá, sean reconocidos como enjuiciables al igual que los perjuicios civiles, los recursos de la ley civil pueden emplearse por un demandante civil extranjero ante los tribunales canadienses. Como tales, las corporaciones canadienses o sus directivos y empleados pueden ser enjuiciados en Canadá por sus conductas punibles en países extranjeros ${ }^{153}$.

Algunas de estas soluciones han sido estudiadas por los académicos ${ }^{154}$ en Canadá, pero solo un caso se ha llevado ante la justicia. En 1998 se presentó una demanda colectiva en un tribunal de Quebec contra Cambior, luego que un embalse defectuoso provocó la contaminación con cianuro de un río en

\footnotetext{
${ }^{151}$ Para información acerca de este caso, consúltese Business and Human Rights Resource Centre, en internet: humanrights.org/Categories/Lawlawsuits/Lawsuitsregulatoryaction/Law suitsSelectedcases/TalismanlawsuitreSudan. Véase también Drohan, ibíd., pp. 321, 323, 327 , quien argumenta que los gobiernos nacionales deben emprender acciones cuando compañías establecidas en sus países sean responsables de infracciones cometidas en el extranjero.

${ }_{152}$ Conferencias Nacionales en torno a la RSC, nota 164, p. 45.

${ }^{153}$ Informe de la Comisión Permanente, "SCFAIT CSR Report", nota 143.

${ }^{154}$ Ver, por ejemplo, Scott y Wai, nota 150, y Lisa North, Timothy David Clark, Viviana Patroni, eds., Community Rights and Corporate Responsibility: Canadian Mining and Oil Companies in Latin America (Toronto: Between the Lines, 2006).
} 
Guyana $^{155}$. Aunque el tribunal había señalado que tanto Guyana como Quebec tenían jurisdicción sobre la materia, decidió que Guyana era el foro más apropiado. Esta decisión se basó fundamentalmente en la fuerte conexión del accidente y sus víctimas con Guyana, y en la ausencia de asociación de los perjudicados con Quebec. El tribunal también indicó que su decisión de no escuchar el caso no negaba la justicia para las víctimas, ya que el sistema judicial guyanés les daría "un trato justo e imparcial"156. Sin embargo, la verdadera causa de esta decisión puede ser la renuencia a hacer un señalamiento negativo sobre los jueces y el sistema legal de otra jurisdicción ${ }^{157}$. Las víctimas presentaron su demanda en los tribunales guyaneses, pero debido a razones procesales fue rechazada en $2002^{158}$.

Los tribunales canadienses pueden estar preocupados por el uso de la ley nacional para tratar de influir en la conducta de las corporaciones fuera del país. La Corte Suprema de Canadá, en el caso Shell Canada Products Ltd. v. Vancouver (City of), falló que la ciudad de Vancouver no tenía jurisdicción para dictar una sentencia contra hacer negocios con Shell Oil. En aquel momento, la ciudad objetaba los vínculos de negocios de la Shell con el régimen del apartheid en Suráfrica ${ }^{159}$.

Los tribunales pueden también mostrarse reluctantes a tomar jurisdicción debido a que debiera haber mecanismos más apropiados para determinar la responsabilidad, incluyendo las recomendaciones hechas por el Comité Asesor. El problema, sin embargo, no puede esperar hasta que entre en funcionamiento un futuro sistema de implementación. La realidad es que en la Guatemala de hoy día hay un déficit en los mecanismos de precisión de responsabilidades - un déficit de la inspección y el control necesarios para responder a los intereses de comunidades indígenas como las de Sipacapa y San Miguel Ixtahuacán.

Hemos visto que el Estado guatemalteco no posee los mecanismos legislativos para asegurar una consulta, ni la capacidad técnica para supervisar

155 Recherches Internationales Québec v. Cambior Inc. (1998), [1998] Q.J. No. 2554, párr. 4 [Cambior].

${ }^{156}$ Ibíd., párrs. 9-12.

${ }_{158}^{157}$ Scott y Wai, nota 150, p. 301.

158 Ibíd., p. 302.

${ }^{159}$ Shell Canada Products v. Vancouver (City of), [1994] 1 Supreme Court Reporter 231. La mayoría de los miembros del tribunal opinaba que la ciudad no tenía jurisdicción para adoptar decisiones basadas en aspectos de la conducta de una corporación en el extranjero. Sin embargo, la decisión fue muy cerrada: 5/4, y el actual presidente del tribunal, McLachlin J, disintió. 
el proyecto. A la vez, sin embargo, se beneficia de los ingresos generados por la mina.

El Banco Mundial estaba consciente de las deficiencias del Estado y de la importancia de los proyectos comunitarios, y proveyó un paquete de ayuda a Guatemala por $\$ 780$ millones de dólares norteamericanos, como se anunció en una nota de prensa de Glamis ${ }^{160}$. Se produjo una propuesta ulterior por el Banco, de otorgar financiamiento al gobierno a fin de asegurar que tuviera la capacidad de supervisar el proyecto ${ }^{161}$. El Banco Mundial también brindó financiamiento a la Fundación Sierra Madre de la Glamis para la realización de proyectos de mejoramiento comunitario ${ }^{162}$. Es necesario recordar, no obstante, que el Banco Mundial tenía también interés en que la mina lograra reintegrar el préstamo que le había hecho.

La supervisión realizada por la CAO brindaba la oportunidad a terceras partes de examinar los compromisos establecidos por Glamis con la CFI a fin de obtener el préstamo. No obstante, la CAO no era verdaderamente "independiente", ya que está financiada por el Banco Mundial y responde a la presidencia de este.

La embajada de Canadá podía, teóricamente, adoptar una posición más neutral, pero esto hubiera requerido que reconsiderara su mandato de apoyar con vigor a las empresas mineras canadienses y sus accionistas cuando se presentaran diferendos entre la mina y las comunidades indígenas ${ }^{163}$.

Si bien la carencia de un contrapeso efectivo resulta problemática, en este caso la interconexión de intereses económicos, políticos y militares agudiza la grave deficiencia de supervisión y control. Hemos analizado las instancias de fijación de responsabilidades que puedan existir: el Estado guatemalteco, el Banco Mundial, la CAO, la embajada de Canadá. Todos estos actores no indígenas estaban interesados en que la mina fuese rentable. Hay en Guatemala muchos políticos, funcionarios, e incluso miembros de las fuerzas armadas, que luchan por dejar atrás el pasado e ir hacia el futuro con integridad, reconociendo los derechos de los pueblos indígenas. Dada la fragilidad de los mecanismos internos de rendición de cuentas, la lucha de estos factores se fortalecería si existiera una efectiva institución externa de

\footnotetext{
${ }^{160}$ Glamis Gold, nota de prensa: "Glamis Gold Comments on World Bank Financial Assistance Program in Guatemala" (19 de mayo de 2005).

161 Informe de la CAO (2005), nota 30, p. 38.

162 Anexo al Informe de la CAO (2005), nota 32, p. 14. El presupuesto operativo anual de la Fundación Sierra Madre es de US $\$ 400 \mathrm{~K}+$, de los cuales la CFI ha aportado $\$ 89 \mathrm{~K}$.

${ }^{163}$ Mackenzie, nota 141, citando a Ginette Martin, consejera política de la embajada canadiense.
} 
supervisión. En la presente situación, indiscutiblemente no ideal, lo mejor que pudiéramos esperar sería que un tribunal canadiense pueda convertirse en un foro que escuche con justeza la evidencia y emita las disposiciones apropiadas.

\section{CONCLUSIONES}

Sabemos que nos hemos centrado en la crítica de las actividades de la Goldcorp, pero el objetivo de este artículo no es resaltar la cuestión, más amplia, de si la minería es "buena" o "mala". Por el contrario, el tema central del presente trabajo es el ejercicio del derecho indígena y el déficit de supervisión y control sobre los poderosos actores económicos que pueden estar violando ese derecho.

Hemos mostrado que el pueblo de Sipacapa intentó que la consulta fuese vinculante. La CAO señaló que la comunidad se sentía "intimidada" por la ola de actividades de exploración, e hizo observaciones sobre los peligros de estas actividades:

Al no disponer de la posibilidad de un proceso formal amplio de mediación, la compañía recurre a un proceso de relaciones bilaterales y negocia en forma individual con las aldeas en lugar de hacerlo con el municipio en su conjunto. El riesgo de este método es que puede ser contrario a las decisiones que, de acuerdo con algunos miembros de la comunidad, fueron adoptadas colectivamente. Esta práctica acentúa las identidades de los grupos cerrados y las divisiones entre los grupos, en lugar de lograr identidades y conexiones más amplias compartidas por todos. También puede socavar la cohesión social, en lugar de aumentarla, y contribuir a la intensification del conflicto. Además, algunos problemas no se resuelven utilizando estrategias bilaterales o unilaterales ${ }^{164}$.

Pese a todas estas significativas circunstancias, la CAO no puede ordenar el acatamiento de sus recomendaciones; solo puede sugerir. En todo caso, la Goldcorp, al reintegrar el préstamo del Banco Mundial, se ha puesto fuera del alcance de la CAO.

La Goldcorp tiene varias minas en funcionamiento, así como diversos proyectos de desarrollo en América Latina, incluyendo México, Argentina, Chile, República Dominicana y Honduras ${ }^{165}$. Protestas contra estos proyectos

\footnotetext{
${ }^{164}$ Seguimiento del Informe de la CAO (2006), nota 69, p. 13.

165 "Propiedades auríferas de Goldcorp"; en internet: Goldcorp http://www.goldcorp.com/gold_projects/
} 
se han producido en comunidades cercanas a las instalaciones mineras. Al igual que en Guatemala, comunidades locales en Honduras han manifestado que no fueron consultadas con respecto al desarrollo de estas actividades ${ }^{166}$. También estas comunidades exponen que sus aguas están siendo contaminadas con plomo y arsénico provenientes de la mina ${ }^{167}$. En Canadá, la Goldcorp dispuso ilegalmente de 11,000 metros cúbicos de desechos en el Red Lake, Ontario, y se le impuso una multa de $\$ 225,999^{168}$. El diario Globe and Mail concedió a la Goldcorp un $\mathrm{D}+{ }^{169}$ en responsabilidad social corporativa ${ }^{170}$.

En Guatemala, la Goldcorp continúa intentando realizar intrusiones en Sipacapa, y no muestra ninguna voluntad por respetar los resultados de la consulta $^{171}$. Existe ahora una creciente oposición a la mina en el vecino municipio de San Miguel Ixtahuacán, que ha culminado en bloqueos y arrestos. En enero de 2007, un ecologista italiano, Flaviano Bianchini, dio a conocer un informe que sugiere que la mina ha provocado problemas con el agua en San Marcos. La Goldcorp respondió diciendo que este estudio era "totalmente incorrecto, si no patentemente falso", y "con toda probabilidad fraudulento" ${ }^{, 72}$. Durante su estancia en Guatemala, Bianchini recibió una cadena de amenazantes llamadas telefónicas anónimas, y fue objeto de vigilancia. Amnistía Internacional emitió un llamado de Acción Urgente al respecto. Temiendo por su seguridad, el ecologista acortó su estancia y regresó a Italia $^{173}$.

166 Anna Cody, "Presentation to the Committee on Economic, Social \& Cultural Rights: Gold Mining in Honduras", online: Center for Economic and Social Rights http://cesr.org/node/62?PHPSESSID=97fa44e2dc20667a749c2fa25b763b99

${ }^{167}$ Stephen Leahy, "Protests Mount Against Mining Giant" (24 de febrero de 2007); en internet: Mines \& Communities http://www.minesandcommunities.org/Action/press1381.htm

${ }^{168}$ Ontario Ministry of the Environment, "Goldcorp Inc. Fined \$225,999 for Noncompliance with Ontario Water Resources Act" (1 de noviembre de 2005); en internet: $<$ http://www.ene.gov.on.ca/envision/news/2005/110101.htm>.

${ }^{169}$ En Canadá, "D" es la nota más baja en un examen escolar. "A+" es la más alta.

170 "CSR Mining" Globe and Mail Update (22 de febrero de 2007); en internet: The Globe and Mail http://www.theglobeandmail.com/servlet/story/RTGAM.20070222.rmcsrmining/BNStory/s pecialROBmagazine.

${ }^{171}$ Dawn Paley, "Turning Down a Gold Mine" (7 de febrero de 2007); en internet: The Tyee, http://thetyee.ca/News/2007/02/07/MarlinProject/. "Goldcorp continúa empleando diversas estrategias para penetrar en Sipacapa, incluyendo la oferta de pago a propietarios individuales para realizar exploraciones en sus tierras, y la entrega a la municipalidad de un 'regalo' de más de $\$ 150,000$ dólares canadienses."

${ }^{172}$ E-mail de Wilhoit, nota 74.

173 "Fear for Safety", nota 60. 
Esta es la clase de situación que pide por una institución efectiva e independiente que pueda establecer responsabilidades. Resulta necesario que sea un organismo que pueda sopesar los intereses y acciones de la Goldcorp y los intereses y derechos de las comunidades indígenas del área. El Comité Asesor de las Conferencias Nacionales ha hecho una serie de recomendaciones para supervisar en el futuro las actividades mineras desde Canadá; pero por el momento la única solución para establecer adecuados mecanismos de supervisión y control es la presentación de demandas ante los tribunales. Esperamos que el sistema judicial canadiense sea lo suficientemente abierto como para entender el papel que puede desempeñar en la atención a la vulnerabilidad social y política de las comunidades indígenas. 